\title{
Study of pulsating flow in close-coupled catalyst manifolds using phase-locked hot-wire anemometry
}

\author{
T. Persoons ( $\square)$, E. VAN DEN Bulck
}

Katholieke Universiteit Leuven, Department of Mechanical Engineering, Celestijnenlaan 300 A, B-3001 Leuven, Belgium

email: tim.persoons@mech.kuleuven.ac.be

tel: $+32-16-322511$

fax: $+32-16-322985$

S. FAUSTO

Bosal, Advanced Engineering and Testing, Lummen, Belgium

\begin{abstract}
Phase-locked sampling has been applied to hot-wire anemometry in order to investigate the pulsating flow inside two types of automotive exhaust manifolds fitted with a close-coupled catalyst. An isothermal dynamic flow bench has been used to compare the catalyst velocity distribution in steady operation to crank angle resolved velocity distributions measured in pulsating flow. The latter were obtained using phase-locked averaging. A rotating valve and a cylinder head have been used to generate the pulsating flow. Experimental results have proven the addition principle, i.e. the time-averaged velocity distribution in pulsating flow is proportional to a specific linear combination of velocity distributions, resulting from steady flow through each runner.
\end{abstract}

Key words close-coupled catalyst, exhaust manifold, pulsating flow, phase locked, ensemble averaging, hot-wire anemometry

\section{List of symbols ${ }^{1}$}

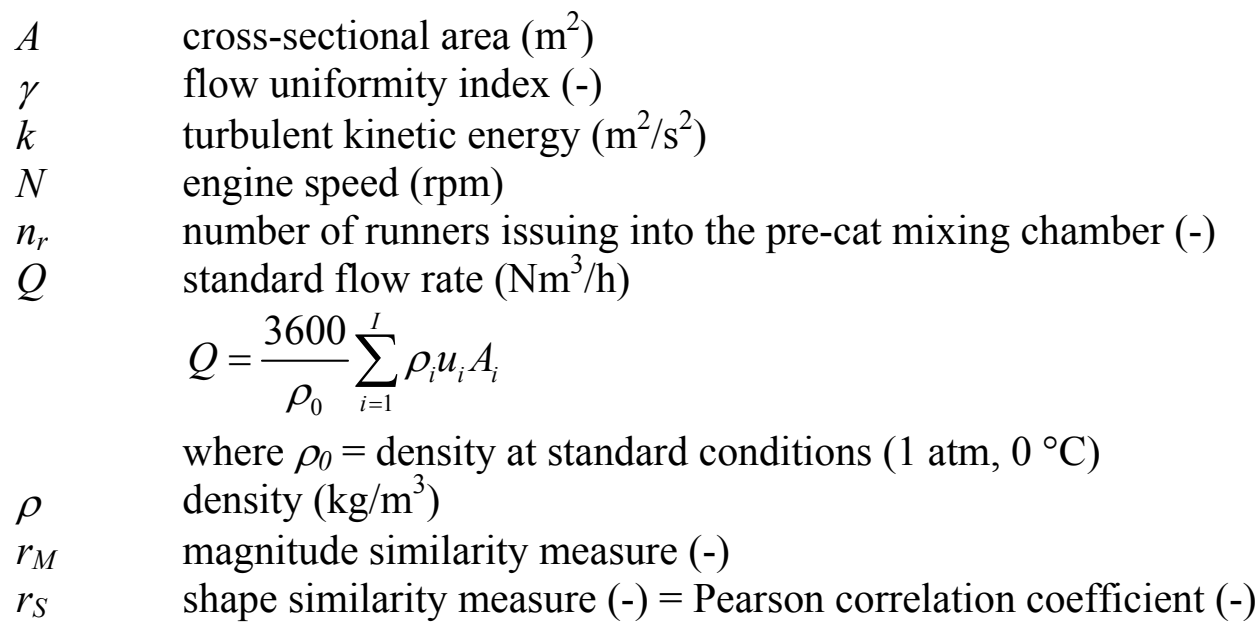

\footnotetext{
${ }^{1}$ For an explanation of data reduction routines, see $\S 3.6$.
} 
Re Reynolds number (-), based on runner hydraulic diameter and mean velocity

$S \quad$ dimensionless scavenging number (-)

$T_{p} \quad$ flow pulsation period ${ }^{2}(\mathrm{~s})$

$$
T_{p}=2 \frac{60}{N} \frac{1}{n_{r}}
$$

$T_{s} \quad$ scavenging time scale (s)

TI turbulence intensity (\%)

$\theta \quad$ crank shaft position $\left({ }^{\circ}\right)$

$u \quad$ axial velocity, perpendicular to measurement plane $(\mathrm{m} / \mathrm{s})$

$\tilde{u} \quad$ dimensionless axial velocity $(-), \tilde{u}=u / u_{m}$

$v, w \quad$ non-axial velocity components $(\mathrm{m} / \mathrm{s})$

$x, y \quad$ coordinates in measurement plane $(\mathrm{mm})$

\section{Subscripts}

dyn unsteady (pulsating) flow

$e \quad e=1 \ldots \mathrm{E}$, index of phase-locked sample records (ensemble coordinate)

$i \quad i=1 \ldots \mathrm{I}$, index of measurement points (spatial coordinate)

$j \quad j=1 \ldots \mathrm{J}$, index of ensemble-averaged samples (temporal, crank shaft position coordinate)

$m \quad$ mean (spatial average)

e.g. $u_{m, j}\left(\theta_{j}\right)=\frac{1}{A} \int_{A} u\left(x, y, \theta_{j}\right) d A=\frac{1}{A} \sum_{i=1}^{I} u_{i, j}\left(x_{i}, y_{i}, \theta_{j}\right) A_{i}$

max maximum value

$$
\text { e.g. } u_{\max }=\max _{i=1 . . I}\left(u_{i}\left(x_{i}, y_{i}\right)\right)
$$

$o \quad$ flow rate measurement orifice conditions

stat steady flow

\section{Introduction}

A high flow distribution uniformity in a catalytic converter is crucial to avoid non-uniform degradation of the catalyst brick due to both chemical and thermal ageing, which has been proven in early research by e.g. Comfort (1974). This is particularly problematic for close-coupled catalysts (CCC) mounted close to the engine exhaust ports, because of the pulsating flow issued by short curved runners into a small pre-cat chamber.

Many researchers have studied flow in a complex engine exhaust manifold, using both experimental and numerical approaches. Phase-locked hot-

\footnotetext{
2 The term 'period' is chosen for clarity; in reality the flow is periodical over one engine cycle period $=n_{r} \cdot T_{p}$, and only quasi-periodical over $T_{p}$.
} 
wire anemometry (HWA) is a widespread measurement technique in the study of turbo machinery internal flow. However, few sources in the literature report on phase-locked HWA for experimental research on flow inside CCC manifolds.

\subsection{Pulsating flow in close-coupled catalyst manifolds}

Arias-Garcia et al. (2001) have performed time-averaged HWA velocity measurements of both steady and pulsating flow in a CCC manifold. Both an isothermal axisymmetric flow bench with rotating disk pulse generator and a motored engine have been used for generating the pulsating flow. Results from the flow bench do not correlate well with the motored engine results, probably due to interaction effects caused by exhaust valve overlap, which was absent in the flow bench set up. The time-averaged velocity distribution in pulsating flow is more uniform than for steady flow. Computational fluid dynamic (CFD) calculations with Star-CD ${ }^{\mathrm{TM}}$ underestimate the velocity magnitude by $50 \%$, thus underestimating flow maldistribution.

On the same set up at Coventry University (UK), Benjamin et al. (2001) have performed a great number of steady and pulsating flow experiments on several types of novel catalyst brick designs, all referenced to a standard type catalyst brick similar to the one used in this research. The results for the standard type brick indicate that flow uniformity increases from steady flow and low pulsation frequencies to high pulsation frequencies, and that flow uniformity decreases for increasing flow rate, both in steady and pulsating flow conditions. This is confirmed in the results reported in this study.

In a recent paper, Benjamin et al. (2002) use an isothermal axisymmetric flow bench for a parametric study of the effect of the diffuser shape (denoted 'precat chamber' in the present paper) on the flow distribution. The authors provide time-resolved velocity data at the inlet and exit of the catalyst brick, for a broad range of pulsation frequency and flow rate. The results are summarised in a correlation of non-uniformity index versus the ratio of pulsation period to diffuser residence time.

Bressler et al. (1996) have performed time-averaged laser-doppler anemometry (LDA) velocity measurements of pulsating flow in a 4-runner manifold with a close-coupled catalyst. Measurements have been performed on an isothermal flow bench with rotating disk to generate the pulsating flow. The 
authors used trace gas injection to determine the load on the catalyst from each cylinder.

Park et al. (1998) and Kim et al. (2002) used phase-locked LDA to measure time-resolved local velocity in a close-coupled catalyst manifold on a fired engine. The authors measured in several points along a straight line upstream of the catalyst brick. The study of Park et al. revealed the existence of a distinct high-frequency velocity oscillation in the post blow-down outlet flow. This phenomenon is also observed in the experiments reported here, and is explained in $\S 4.1 .2$. The authors conclude that measurement data and results of dynamic CFD predictions using Star-CD ${ }^{\mathrm{TM}}$ are in good agreement, although this comparison appears questionable.

Many more researchers have performed velocity distribution measurements on steady flow through close-coupled catalyst manifolds (e.g. Breuer et al. (2000), Voeltz et al. (1999), Nagel and Diringer (2000)). Most of these studies are aimed at maximizing the flow uniformity, while minimizing the pressure drop, often through parametric studies of diffuser and runner geometry or mechanical flow dispersers.

\subsection{Phase-locked hot-wire anemometry}

Identifying time-resolved flow patterns requires phase-locked sampling (also referred to in the literature as conditional sampling). Two data records are phase-locked when their time bases are referenced to a common starting point, usually defined by a once-per-cycle trigger signal. Real-life periodic flows consist of a time-resolved and an unresolved component resulting from random phenomena such as vortex shedding, flow separation, etc. Phase-locked sample records are ensemble-averaged to reduce the contribution of the unresolved component, thus revealing the cycle-resolved flow.

Phase-locked sampling has been widely used in the study of turbo machinery internal flow, because of the flow periodicity. Many papers report on phase-locked LDA or HWA measurements. For instance, Ubaldi et al. (1996) have investigated stator-induced unsteadiness in the outflow from a centrifugal compressor's impeller. A once-per-revolution reference signal triggers the HWA measurement. Several hundred phase-locked sample records are ensembleaveraged, resulting in an estimated uncertainty level of $1 \%$ on mean velocity and 
$5 \%$ on turbulence intensity. Similar instrumentation (see $\S 3.5$ ) and data reduction (see §3.6) are used in this study.

A disadvantage of HWA is its inability to measure reverse flow. In closecoupled catalyst manifolds, reverse flow through the catalyst brick is known to occur in a fired engine. It has been measured e.g. by Park et al. (1998): Fig. 8b shows localised reverse flow inside the catalyst during some short time periods. The possibility of reverse flow occurring in our isothermal set up is smaller because no sonic blow-down occurs (see §3.3). This assumption is supported by phase-locked LDA velocity data from Hwang et al. (1995) obtained on an isothermal flow bench with a cylinder head mounted CCC manifold. Fig. 11 (120 $\left.\mathrm{Nm}^{3} / \mathrm{h}, 2000 \mathrm{rpm}\right)$ and Fig. $13\left(205 \mathrm{Nm}^{3} / \mathrm{h}, 4000 \mathrm{rpm}\right)$ in Hwang et al. both show no reverse flow inside the catalyst.

A reference work on HWA measurement techniques by Bruun (1995) contains an extensive literature survey on conditional sampling and phase-locked averaging applied to HWA and LDA. The survey is subdivided into rotating wake phenomena (e.g. turbo machinery internal flow) (pp. 343-351) and internal combustion engine flow, both in-cylinder (pp. 354-355) and intake system flow (pp. 354). However, engine exhaust flow is not included, since not much research has been conducted in this application field so far.

\section{Objectives}

Designing a CCC exhaust manifold for high catalyst flow uniformity is a challenging task, because of the highly unsteady flow in a complex geometry. Since unsteady CFD calculations of a pulsating flow are associated with a high computational cost, it would be advantageous to be able to use steady CFD calculations to predict flow behaviour in pulsating conditions.

The purpose of this work is to prove or disprove the addition principle, i.e. the time-averaged velocity distribution in pulsating flow is proportional to a linear combination of velocity distributions, resulting from steady flow through each runner, with equal time-averaged flow rate in steady and pulsating flow.

This paper discusses the experimental results for a 3-runner CCC manifold (denoted 'manifold A') designed for a V6-engine, and a 4-runner CCC manifold (denoted 'manifold B') designed for an I4-engine. The reason for choosing these manifolds is clear: since the exhaust valves are open during approximately 240 
${ }^{\circ} \mathrm{ca}$ (degrees crank shaft angle), manifold A features no exhaust valve overlap, i.e. no two cylinders are issuing into the manifold at the same time. On the other hand, manifold $\mathrm{B}$ features an exhaust valve overlap of approximately $60^{\circ} \mathrm{ca}$. The current choice of geometries allows investigation of the effect of exhaust valve overlap on the validity of the addition principle.

\section{Experimental set up}

An experimental set up has been designed to generate a pulsating flow inside a close-coupled catalyst manifold. The limitations of the test rig with regard to flow similarity to a fired engine are discussed. Since measurement results should be compared to CFD predictions, much attention is paid to the boundary conditions of the flow in the manifold. Finally, the instrumentation and data reduction are discussed.

\subsection{Close-coupled catalyst manifolds}

Manifold A is designed for a 3.01 V-6 engine (double overhead camshaft, 4 valves per cylinder, one CCC for each cylinder bank). Manifold B (see Fig. 3.1, bottom) is designed for a 1.21 I-4 engine (double overhead camshaft, 4 valves per cylinder). Table 3.1 lists the detailed specifications. The upstream exhaust gas oxygen sensor has been removed for both manifolds.

Table 3.1: Specifications of manifolds $A$ and $B$

\begin{tabular}{llcc}
\hline & & manifold A & manifold B \\
\hline catalyst & type $^{3}$ & \multicolumn{2}{c}{ ceramic $600 \mathrm{cpsi} / 3$ mil, } \\
& square cross-section channels
\end{tabular}

${ }^{3}$ Cell density is expressed in cpsi (= number of cells per square inch), wall thickness is expressed in $\operatorname{mil}(1 \mathrm{mil}=25.4 \mu \mathrm{m})$. 


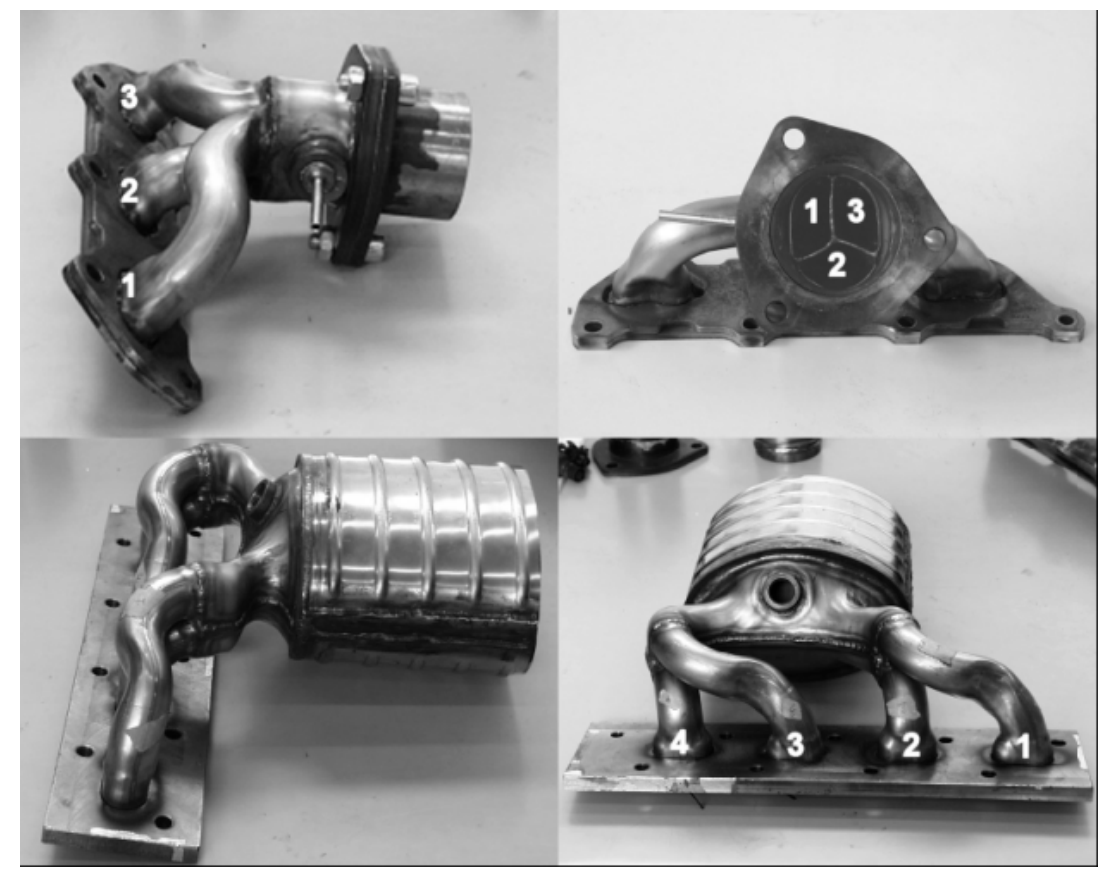

Fig. 3.1: Manifolds A (top) and B (bottom)

\subsection{Dynamic flow bench}

The isothermal dynamic flow bench consists of a surge vessel with removable duct section and mounting plate (see Fig. 3.2). The roots compressor delivers a maximum of $350 \mathrm{Nm}^{3} / \mathrm{h}$ at 300 mbar overpressure. The compressor feeds the surge vessel via a pipe section with a normalised flow rate measurement orifice. According to ISO Standard 5167-2, the orifice should only be used for measuring steady or slowly varying flow rates. The surge vessel has been designed to provide adequate damping of the pulsations caused by the pulsating flow generator (i.e. rotating valve or cylinder head), as prescribed in ISO Technical Report 3313. The additional uncertainty on the orifice flow rate reading in pulsating flow due to using the time-averaged value of the differential pressure is below $0.5 \%$ for all measurement conditions. However, the orifice reading is only used during steady operation to check the flow rate calculated from the velocity distribution. The agreement is well within error bounds (see e.g. Fig. 4.11).

Both a rotating valve and the original cylinder head have been used to generate the pulsating flow: the rotating valve consists of a solid cylinder with rectangular holes, rotating in a stator. The geometry of the holes corresponds to the exhaust valve timing of the cylinder head for manifold A. 


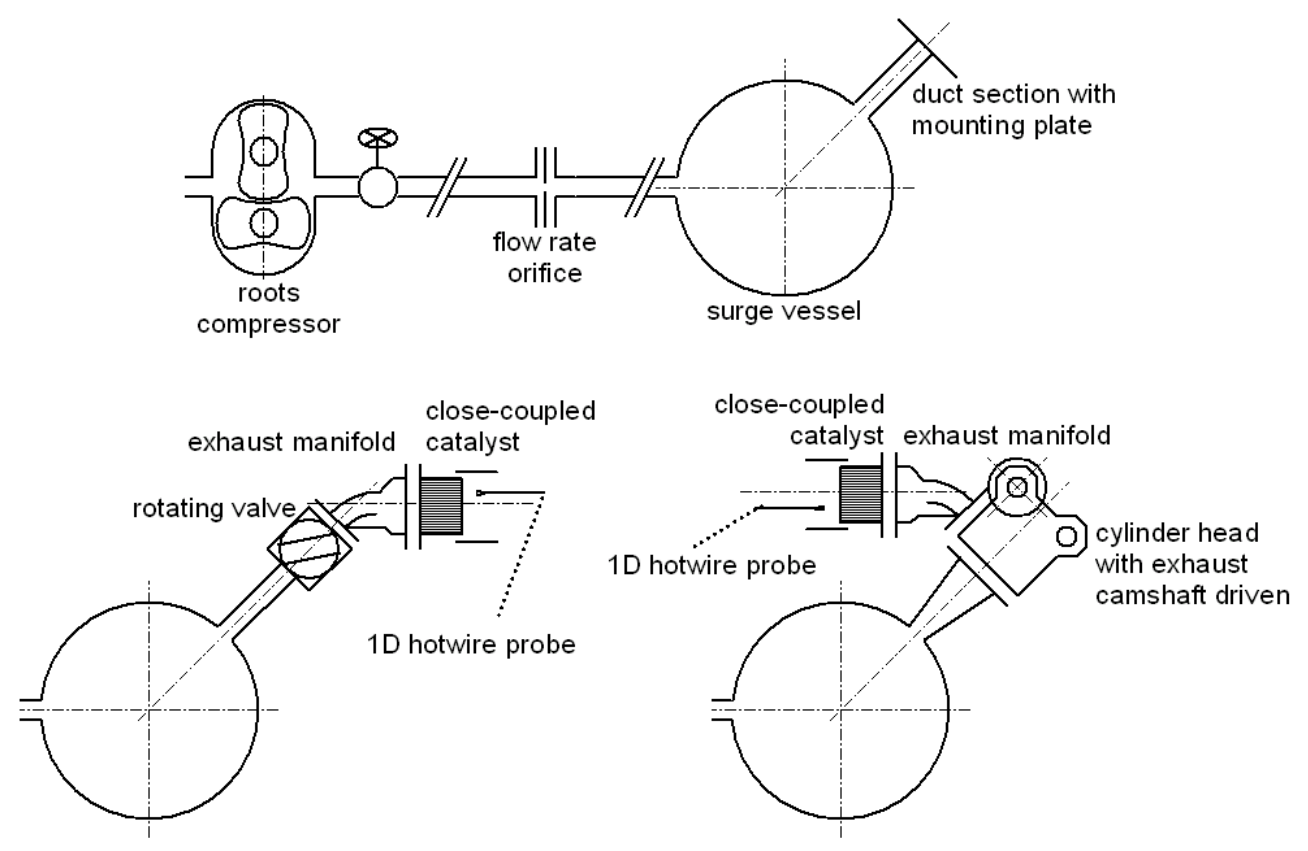

Fig. 3.2: Schematic of isothermal dynamic flow bench (top); generation of pulsating flow with rotating valve (bottom left) and cylinder head (bottom right)

\subsection{Flow similarity}

The exhaust stroke of a fired engine consists of two phases: the blow-down and displacement phase. During blow-down, the gas expands from the residual cylinder pressure to the exhaust manifold pressure, reaching sonic speed at the exhaust valve throat section. This phase is characterised by high flow rate and flow rate transients, limited only by exhaust valve choking. During the displacement phase the upward motion of the piston further expels the gas from the cylinder. This phase is characterised by low mass flow rate and flow rate transients.

The surge vessel in the dynamic flow bench creates a more or less constant pressure upstream of the rotating valve or cylinder head. It thus mimics flow from infinitely large cylinders into the exhaust system. The roots compressor limits the maximum overpressure inside the surge vessel to $300 \mathrm{mbar}$, which is not enough to generate a sonic blow-down. In the case of manifold A, Fig. 3.3a shows a calculated crank angle resolved evolution of exhaust runner mass flow rate and exhaust valve throat Mach number during the exhaust stroke, for both a fired engine and the dynamic flow bench, for the same engine speed and time-averaged flow rate. For illustration, the measured mass flow rate in runner 1 is plotted in dotted line in Fig. 3.3a. 
(a)

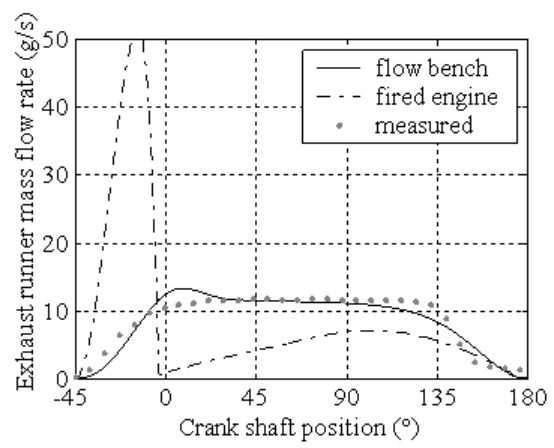

(b)

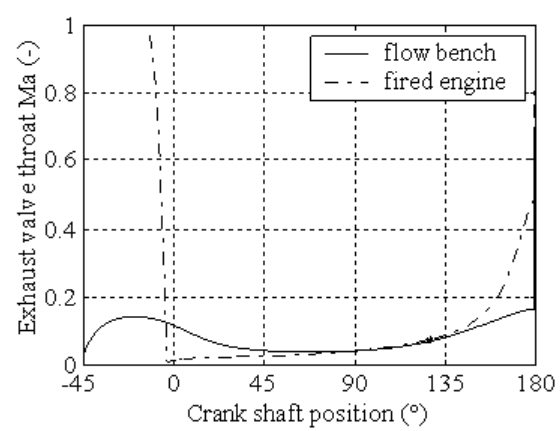

Fig. 3.3: Calculated evolution of (a) mass flow rate (g/s) and (b) exhaust valve throat Mach number during exhaust stroke of (solid) isothermal dynamic flow bench and (dashed) fired engine, for $2000 \mathrm{rpm}$ and a flow rate of $70 \mathrm{Nm}^{3} / \mathrm{h}$

The flow bench cannot produce a pulsating flow identical to the one in a fired engine. However, since the experimental results will be used for validating CFD predictions, the primary design criterion is to have well-defined boundary conditions for the flow inside the manifold.

(a)

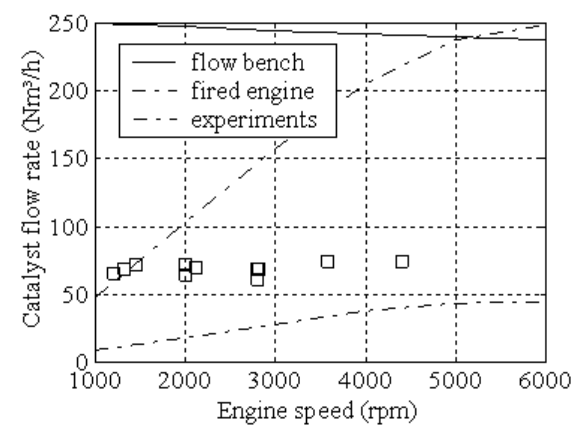

(b)

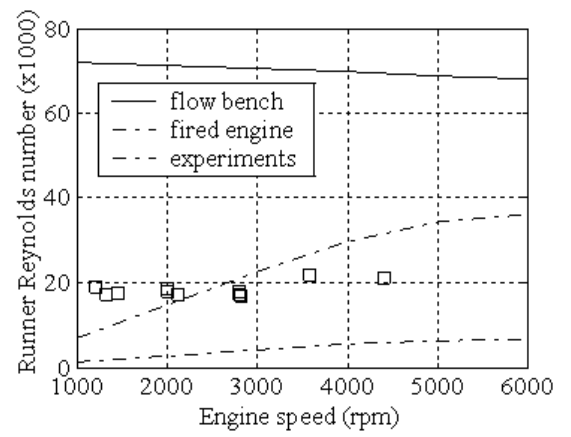

(c)

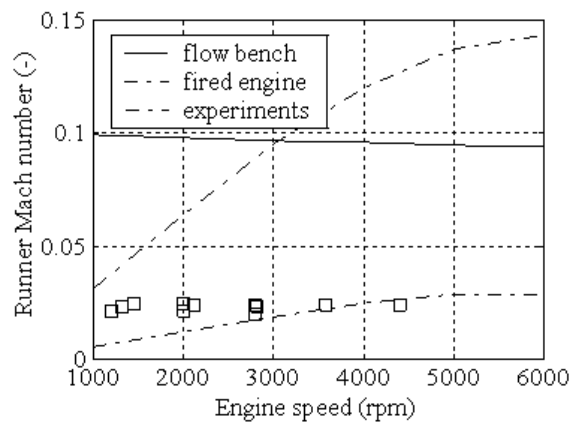

Fig. 3.4: Operating limits of (dashed) fired engine and (solid) flow bench: (a) catalyst volumetric flow rate, runner (b) Reynolds number and (c) Mach number

Fig. 3.4 shows the operating limits for both a fired engine and the flow bench. Indicated by squares are selected experimental conditions. The normal flow rate, Mach and Reynolds number correspond roughly to fired engine conditions. These are time-averaged quantities; the comparison does not hold on the crank angle resolved level.

\subsection{Boundary conditions}

In between the rotating valve or cylinder head and the manifold, a flow straightener is mounted, since making the inlet flow one-dimensional facilitates applying the boundary conditions in CFD calculations. Since the manifold's complex geometry prevented the use of a honeycomb of sufficient length, a screen 
is placed at the manifold inlet. The screen is $1.5 \mathrm{~mm}$ thick, with circular holes (diameter $1.75 \mathrm{~mm}$ ), $3.5 \mathrm{~mm}$ apart in a triangular pattern.

The influence of the flow straightener is investigated in steady flow using a three-dimensional velocity measurement. At $25 \mathrm{~mm}$ downstream from the flow straightener, the mean non-axial velocity components $(v, w)$ are reduced by roughly $40 \%$ with the screen in place, compared to without the screen.

Turbulence intensity has been measured at the exhaust ports. Turbulence intensity $T I(\%)$ and turbulent kinetic energy $k\left(\mathrm{~m}^{2} / \mathrm{s}^{2}\right)$ are defined as

$$
T I=100 \frac{u^{\prime}}{u_{m}}, k=\frac{1}{2}\left(u^{\prime}\right)^{2}
$$

where $u^{\prime}=$ turbulent velocity fluctuation $(\mathrm{m} / \mathrm{s})$; the velocity standard deviation defined in $\$ 3.6$ is chosen as a measure for $u^{\prime}$.

Table 3.2 demonstrates that the screen does not have a significant impact on the turbulence intensity level and neither on the flow uniformity index (see Eq. 3.6 ) at the inlet of the manifold. Mean turbulence intensity amounts to $11 \%$ for steady flow, and to $16 \%$ for pulsating flow. The flow uniformity index is in both cases around 0.95 .

The Reynolds number is defined as

$$
\operatorname{Re}=\frac{u_{m} D_{h}}{v}
$$

where $u_{m}=$ runner mean velocity $(\mathrm{m} / \mathrm{s}), D_{h}=$ runner hydraulic diameter $(\mathrm{m})(=$ $31.5 \mathrm{~mm}$ for manifold A, $28.0 \mathrm{~mm}$ for manifold B), $v=$ kinematic viscosity $\left(\mathrm{m}^{2} / \mathrm{s}^{2}\right)$.

Table 3.2: Boundary conditions at inlet of manifold A (runner 1) in steady flow conditions, (a)

\begin{tabular}{|c|c|c|c|c|}
\hline & (a) & (b) & & \\
\hline$u_{m}$ & 26.6 & 28.2 & $\pm 0.6 \%{ }^{4}$ & $(\mathrm{~m} / \mathrm{s})$ \\
\hline$\sqrt{v_{m}^{2}+w_{m}^{2}} / u_{m}$ & 0.0722 & 0.0449 & $\pm 10.0 \%$ & $(-)$ \\
\hline$R e$ & 51400 & 54400 & $\pm 2.0 \%$ & $(-)$ \\
\hline$Q_{o}$ & 94.6 & 95.0 & $\pm 5.0 \%$ & $\left(\mathrm{Nm}^{3} / \mathrm{h}\right)$ \\
\hline$\gamma$ & 0.958 & 0.943 & $\pm 0.1 \%$ & $(-)$ \\
\hline$u_{m} / u_{\max }$ & 0.890 & 0.842 & $\pm 5.0 \%$ & $(-)$ \\
\hline$k_{m}$ & 4.388 & 4.885 & $\pm 9.9 \%$ & $\left(\mathrm{~m}^{2} / \mathrm{s}^{2}\right)$ \\
\hline$T I_{m}$ & 11.1 & 11.0 & $\pm 7.0 \%$ & $(\%)$ \\
\hline
\end{tabular}
without and (b) with screen

An outlet sleeve is mounted onto the outlet of the manifold, in order to avoid entrainment of surrounding air in the measurement plane. The outlet sleeve

\footnotetext{
${ }^{4}$ These values are estimated experimental uncertainties, based on a $95 \%$ confidence level.
} 
is a $40 \mathrm{~mm}$ long extension of the pipe section holding the catalyst brick. All measurements are performed inside the outlet sleeve. The measurement plane is located at an experimentally determined distance of $25 \mathrm{~mm}$ from the outlet of the catalyst brick, such that the jets issuing from the catalyst brick channels are sufficiently mixed after this distance. Other researchers mention using a similar distance. Arias-Garcia et al. (2001) measure $30 \mathrm{~mm}$ downstream, based on previous research in their laboratory by Clarkson (1995). Experiments by Lemme and Givens (1974) show the effect of the jets to disappear after roughly 1 inch.

In turbulent flow conditions, the hydrodynamic entry length in a tube with circular cross-section is independent of $\operatorname{Re}$ and $\operatorname{Pr}$, and generally assumed to be larger than 10 diameters (see Incropera and DeWitt (1996)). Therefore, the flow issuing from the catalyst brick is far from fully developed after $25 \mathrm{~mm}$, so most information about the true flow distribution inside the brick will be present in the measured distribution at that point.

\subsection{Instrumentation}

A Dantec StreamLine ${ }^{\mathrm{TM}}$ constant temperature HWA system with Dantec type $90 \mathrm{C} 10$ constant temperature anemometer modules has been used for the velocity measurements. The flow downstream of the catalyst is assumed onedimensional, since the catalyst brick acts as a perfect flow straightener. As such a one-dimensional hot-wire probe is chosen (type 55P11: platinum-plated tungsten wire, diameter $5 \mu \mathrm{m}$, length $1.25 \mathrm{~mm}$ ), limiting the maximum spatial resolution to measurement grid cell cross-sections of $1.5 \mathrm{~mm}^{2}$. For the inlet boundary condition measurements at the exhaust ports, a two-dimensional crossed hot-wire probe is chosen (type 55P61). By rotating the probe about its axis over $90^{\circ}$, a threedimensional velocity measurement is performed. The probes are calibrated with a Dantec type 90H02 automated calibration unit.

In order to measure the crank angle resolved velocity, a signal to trigger the velocity measurement is applied to the HWA PC's data-acquisition board. A second PC, equipped with a dSPACE data acquisition board for real-time control generates this trigger. It reads the position of the rotating valve or exhaust camshaft by means of a high-resolution incremental encoder (angular error smaller than $0.1^{\circ}$ ) generates the trigger signal. 
A Dantec 41T50 traverse system has enabled the automatic positioning of the velocity probe in a predefined grid (positioning error smaller than $0.25 \mathrm{~mm}$ ).

For manifold A, stationary velocity measurements are performed using a grid of 1576 points (average grid cell cross-sectional area of $2.3 \mathrm{~mm}^{2}$ ) 5 . Dynamic velocity measurements are performed using a grid with 271 points (average grid cell cross-sectional area of $13.4 \mathrm{~mm}^{2}$ ). Corresponding grids are used for manifold B.

\subsection{Data reduction}

For the stationary velocity measurements, 400 samples are taken in each grid point at a sampling rate of $100 \mathrm{~Hz}$. An initial autocorrelation measurement ${ }^{6}$ resulted in an integral time scale around $0.75 \mathrm{~ms}$. Taking 400 samples results in an estimated relative error of $0.2 \%$ on local velocity $u_{i}\left(x_{i}, y_{i}\right)$ and $1.0 \%$ on mean velocity $u_{m}$.

In steady flow conditions, the local instantaneous velocity consists of a time-averaged component $u_{i}\left(x_{i}, y_{i}\right)$ and a fluctuating component, caused by turbulence. The velocity standard deviation (i.e. the root-mean-square of the fluctuating component) is used as a measure for turbulent velocity fluctuation $u_{i}^{\prime}\left(x_{i}, y_{i}\right)$ in Eq. 3.1.

In pulsating flow, ensemble averaging is applied to the velocity measurements. In each grid point, 25 phase-locked ensembles of 80 consecutive samples are taken at a sampling rate proportional to the rotating valve or camshaft rotation speed. Thus 80 samples correspond to 80 crank angle positions, i.e. one sample every $720 / 80=9^{\circ} \mathrm{ca}$. Each record's time base is relative to the dSPACE PC's trigger pulse (see §3.5). The number of ensembles necessary to reduce estimated uncertainty depends on the magnitude of the unresolved fluctuating component. In turbo machinery flow research, values from 100 to 300 are typical (see Bruun (1995)); in this study, 25 ensembles proved enough to reduce estimated uncertainty on mean velocity below $1 \%$.

\footnotetext{
${ }^{5}$ For comparison, Arias-Garcia, et al. (2001) and Benjamin, et al. (2001) use a measurement grid with average cell cross-sectional area of $6.25 \mathrm{~mm}^{2}$.

${ }^{6}$ Velocity autocorrelation measurement at $30 \mathrm{kHz}$ in steady flow $\left(u_{m}=12.4 \mathrm{~m} / \mathrm{s}\right)$ downstream of the catalyst.
} 
In pulsating flow, the local instantaneous velocity $u_{i, j, e}\left(x_{i}, y_{i}, \theta_{j}\right)$ consists of an ensemble-averaged component $u_{i, j}\left(x_{i}, y_{i}, \theta_{j}\right)$

$$
u_{i, j}\left(x_{i}, y_{i}, \theta_{j}\right)=\frac{1}{E} \sum_{e=1}^{E} u_{i, j, e}\left(x_{i}, y_{i}, \theta_{j}\right)
$$

where $e=$ ensemble coordinate, and a fluctuating component caused by unresolved random phenomena. The fluctuating component is characterised by the standard deviation $\operatorname{std}\left(u_{i, j}\left(x_{i}, y_{i}, \theta_{j}\right)\right)$, defined as:

$$
\operatorname{std}\left(u_{i, j}\right)=\sqrt{\frac{1}{E} \sum_{e=1}^{E}\left(u_{i, j, e}-u_{i, j}\right)^{2}}
$$

The standard deviation is used in Eq. 3.1 for the calculation of turbulent kinetic energy and turbulence intensity. The ensemble-averaged component $u_{i, j}\left(x_{i}, y_{i}, \theta_{j}\right)$ is the crank angle resolved local velocity in grid point $\left(x_{i}, y_{i}\right)$. Since the number of samples $J$ is fixed and the sampling rate is chosen such that $J$ samples correspond to $720^{\circ} \mathrm{ca}$ (i.e. one engine cycle), the crankshaft position $\theta$ is equivalent to the sample index $j=J(\theta / 720)$ or to time $t=2(60 / N)(\theta / 720)$. The time-averaged velocity (or crank angle average velocity) is defined as

$$
\bar{u}_{i}\left(x_{i}, y_{i}\right)=\frac{1}{J} \sum_{j=1}^{J} u_{i, j}\left(x_{i}, y_{i}, \theta_{j}\right)
$$

where $j=$ sample coordinate $(=$ crank coordinate $=$ time coordinate $)$.

In all figures of velocity distributions in the following section, the dimensionless velocity (-) is plotted, defined as $\tilde{u}(x, y)=u(x, y) / u_{m}$ for a steady flow measurement, and $\tilde{u}(x, y, t)=u(x, y, t) / \bar{u}_{m}$ for a pulsating flow measurement.

Flow uniformity is quantified using two different measures: flow uniformity index $\gamma(-)$ and mean-to-maximum velocity ratio $u_{m} / u_{\max }\left(=1 / \tilde{u}_{\max }\right)(-)$. The flow uniformity index $\gamma$ introduced by Weltens et al. (1993) is the most generally accepted uniformity measure in this research field. It is defined as

$$
\gamma=1-\frac{1}{2 u_{m} A} \sum_{i=1}^{I}\left|u_{i}-u_{m}\right| A_{i}
$$

where $u_{i}=$ velocity in $\left(x_{i}, y_{i}\right)$ and $A_{i}=$ cross-sectional area of grid cell i, $u_{m}$ the mean velocity, $A=$ total cross-sectional area. Although Weltens' uniformity index is generally accepted, the measure has its drawbacks. Therefore, the mean-tomaximum velocity ratio $u_{m} / u_{\max }$ is also given as a uniformity measure in the 
figures below. Both measures reach a maximum value of unity for a uniform flow and decrease as flow uniformity decreases.

$\S 4.3$ discusses the similarity ${ }^{7}$ between the averaged steady velocity distribution and the time-averaged velocity distributions observed in pulsating flow. The similarity is quantified using two measures with respect to magnitude and shape of the velocity distribution. The magnitude similarity measure $r_{M}(-)$ is based on the mean-to-maximum velocity ratio:

$$
r_{M}=\frac{\left(u_{m} / u_{\max }\right)_{d y n}}{\left(u_{m} / u_{\max }\right)_{\text {stat }}}=\frac{\left(1 / \tilde{u}_{\max }\right)_{d y n}}{\left(1 / \tilde{u}_{\max }\right)_{\text {stat }}}=\frac{\left(\tilde{u}_{\max }\right)_{\text {stat }}}{\left(\tilde{u}_{\max }\right)_{d y n}}
$$

$r_{M}$ expressed the relative increase in flow uniformity (based on the mean-tomaximum velocity ratio) in pulsating flow, compared to the averaged steady velocity distribution.

The Pearson correlation coefficient acts as shape similarity measure $r_{S}(-)$, since it quantifies similarity based on the shape of the velocity distribution:

$$
r_{S}=\frac{\sum_{i=1}^{I}\left(\left(u_{i, 1}-u_{m, 1}\right)\left(u_{i, 2}-u_{m, 2}\right)\right)}{\sqrt{\sum_{i=1}^{I}\left(u_{i, 1}-u_{m, 1}\right)^{2} \cdot \sum_{i=1}^{I}\left(u_{i, 2}-u_{m, 2}\right)^{2}}}
$$

where $u_{i, k}=$ local velocity in $\left(\mathrm{x}_{\mathrm{i}}, \mathrm{y}_{\mathrm{i}}\right)$ and $u_{m, k}=$ mean velocity in experiment $\mathrm{k}$. Definitions of $r_{M}$ and $r_{S}$ are such that $r_{M}$ is insensitive to the difference in shape of the two velocity distributions, and $r_{S}$ is insensitive to the difference in magnitude of the two velocity distributions. Both measures are necessary to compare two velocity distributions.

The pulsating flow in a CCC manifold enforces a periodic scavenging of the pre-cat mixing chamber into the catalyst. The pre-cat chamber volume and the volume of exhausted gas per cylinder per cycle, as well as the layout of the runners issuing into the pre-cat chamber, determine the scavenging process.

The scavenging time scale $T_{s}(\mathrm{~s})$ is defined as the ratio of pre-cat mixing chamber volume to time-averaged volumetric flow rate through the catalyst:

$$
T_{s}=\frac{V_{\text {pre-cat chamber }}}{\sum_{i=1}^{I} \bar{u}_{i} A_{i}}
$$

\footnotetext{
${ }^{7}$ Note that in order to check the validity of the addition principle, the velocity distributions tested for similarity have equal time-averaged flow rate, thus equal $u_{m}$.
} 
The flow regime can be characterised by the dimensionless scavenging number $S(-)$, defined as the ratio of flow pulsation period $T_{p}(\mathrm{~s})$ to scavenging time scale $T_{s}$ :

$$
S=\frac{T_{p}}{T_{s}}
$$

If $S$ is large (e.g. low engine speed or high flow rate per pre-cat volume), the pre-cat chamber scavenging occurs faster than the flow pulsation, so the flow distribution should be relatively unaffected by engine speed. If $S$ is small (e.g. high engine speed or low flow rate per pre-cat volume), the opposite is true and interference of the pulses in the pre-cat chamber result in an engine speed dependent flow distribution.

Other researchers use equivalent dimensionless numbers for characterizing pulsating flow in a CCC manifold. Benjamin et al. (2002) define $J(-)$ as the ratio of pulsation period to diffuser (i.e. pre-cat mixing chamber) residence time, where the residence time is defined in terms of diffuser length and inlet mean velocity. Bressler et al. (1996) define GEN (-) (gas exchange number) as the ratio of exhausted gas volume per cylinder per cycle to the pre-cat mixing chamber volume. Both papers present relationships between flow uniformity in pulsating flow and this dimensionless number. The results of this study are compared to the findings of Benjamin et al. (2002) and Bressler et al. (1996) in $§ 4.3$.

\section{Experimental results}

The velocity measurements in pulsating flow are discussed, first timeaveraged and then time-resolved. Next, the velocity measurements in steady flow are discussed, and finally, the measurements in steady and pulsating flow are compared using the similarity measures defined in $\S 3.6$.

\subsection{Unsteady velocity measurements}

The unsteady velocity measurements have been performed by driving the rotating valve or exhaust camshaft at a constant speed. Phase-locked averaging has been applied as described in $\S 3.6$. 


\subsubsection{Time-averaged}

Fig. 4.1 shows the time-averaged velocity distribution for manifold A using respectively the rotating valve and cylinder head as pulsating flow generator, for a comparable engine speed. The distributions at other engine speeds are not shown since they are very similar. The last but one column in Fig. 4.1 and following figures shows the relative experimental uncertainty, based on a $95 \%$ confidence level.

Despite the different ways of generating the pulsating flow, the timeaveraged flow distributions in Fig. 4.1 appear rather similar. The similarity is very high and is quantified in Table 4.1 by calculating the correlation coefficient $r_{S}$ for each combination of two distributions at comparable engine speeds.

(a)

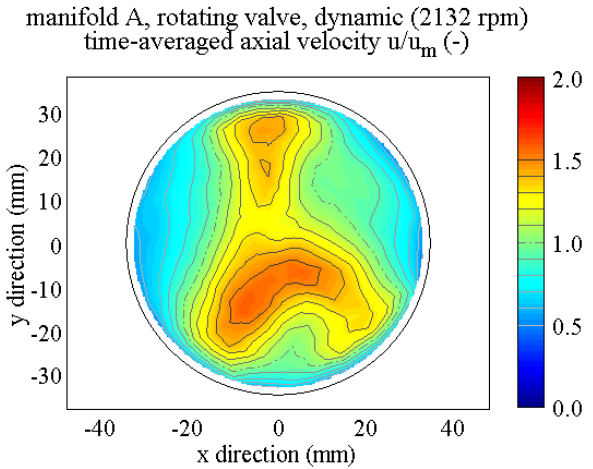

(b)

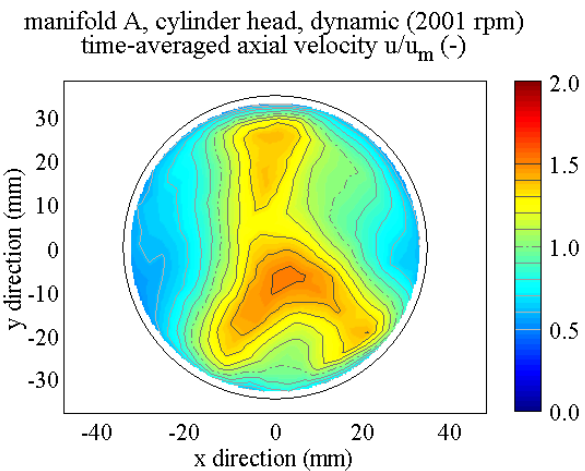

\begin{tabular}{cccc|ccccc}
\hline \multicolumn{7}{c|}{ manifold A, rotating valve } & \multicolumn{5}{c}{ manifold A, cylinder head } \\
\hline$N$ & 1452 & 2132 & 2822 & 1327 & 2001 & 2800 & $\pm 0.5 \%$ & $(\mathrm{rpm})^{8}$ \\
\hline $\bar{u}_{m}$ & 5.62 & 5.55 & 5.36 & 5.52 & 5.77 & 5.54 & $\pm 0.1 \%$ & $(\mathrm{~m} / \mathrm{s})$ \\
\hline$\overline{R e}$ & 17600 & 17400 & 16833 & 17300 & 18100 & 17400 & $\pm 1.9 \%$ & $(-)$ \\
\hline $\bar{Q}$ & 71.6 & 70.0 & 67.8 & 68.2 & 71.9 & 68.8 & $\pm 1.2 \%$ & $\left(\mathrm{Nm}^{3} / \mathrm{h}\right)$ \\
\hline$\gamma$ & 0.863 & 0.872 & 0.873 & 0.860 & 0.867 & 0.895 & $\pm 0.1 \%$ & $(-)$ \\
\hline$u_{m} / u_{\max }$ & 0.622 & 0.644 & 0.635 & 0.611 & 0.644 & 0.699 & $\pm 2.0 \%$ & $(-)$ \\
\hline$S=T_{p} / T_{s}$ & 4.37 & 2.91 & 2.13 & 4.56 & 3.19 & 2.18 & $\pm 2.2 \%$ & $(-)$ \\
\hline
\end{tabular}

Fig. 4.1: Distribution of dimensionless time-averaged velocity ${ }^{9} \bar{u} / \bar{u}_{m}(-)$, for manifold A using rotating valve (left) and cylinder head (right)

\footnotetext{
${ }^{8}$ All values expressed in rpm are corresponding engine (crankshaft) speed $=2 \mathrm{x}$ exhaust camshaft speed $=4 \mathrm{x}$ rotating valve speed.

${ }^{9}$ Contour lines are 0.1 units apart, ranging from white to black, with a dashed contour at unity.
} Note that flow uniformity measures $\gamma, u_{m} / u_{\max }$ are calculated from the time-averaged velocity distribution, e.g. $\gamma=1-\frac{1}{2 \bar{u}_{m} A} \sum_{i=1}^{I}\left|\bar{u}_{i}-\bar{u}_{m}\right| A_{i}$. 
Table 4.1: Correlation coefficient $r_{S}(-)$ between velocity distributions obtained for manifold A using rotating valve and cylinder head at comparable engine speeds

\begin{tabular}{ccccc}
\hline$N$ & $\cong 1400$ & $\cong 2000$ & $\cong 2800$ & $(\mathrm{rpm})$ \\
\hline$r_{S}$ & $0.957( \pm 0.9 \%)$ & $0.948( \pm 1.1 \%)$ & $0.942( \pm 1.3 \%)$ & $(-)$ \\
\hline
\end{tabular}

Fig. 4.1 shows that for manifold A, the dimensionless scavenging number $S$ is larger than unity, meaning that the scavenging time scale is smaller than the pulsation period. It that case, one would expect only a minor influence of the engine speed on flow distribution, which is confirmed in Fig. 4.1 by the values for flow uniformity index and mean-to-maximum velocity.

Fig. 4.2 presents corresponding results for manifold B. The higher flow uniformity compared to manifold $\mathrm{A}$ is due to the complex geometry with runners entering the pre-cat mixing chamber at a high angle of attack with respect to the brick inlet face.

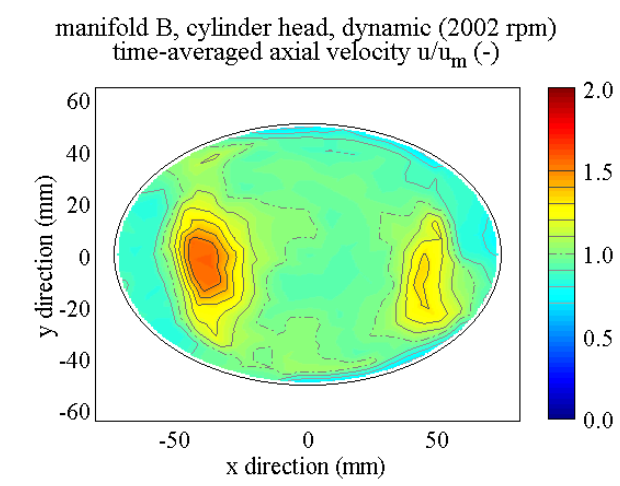

\begin{tabular}{cccccccc}
\hline \multicolumn{7}{c}{ manifold B, cylinder head } \\
\hline$N$ & 609 & 1203 & 2002 & 2803 & 3595 & $\pm 0.5 \%$ & $(\mathrm{rpm})$ \\
\hline $\bar{u}_{m}$ & 1.52 & 1.66 & 1.64 & 1.57 & 1.897 & $\pm 0.1 \%$ & $(\mathrm{~m} / \mathrm{s})$ \\
\hline$\overline{R e}$ & 17500 & 19200 & 18800 & 17900 & 21700 & $\pm 2.1 \%$ & $(-)$ \\
\hline $\bar{Q}$ & 59.5 & 65.0 & 64.4 & 60.4 & 73.9 & $\pm 1.6 \%$ & $\left(\mathrm{Nm}^{3} / \mathrm{h}\right)$ \\
\hline $\bar{\gamma}$ & 0.933 & 0.942 & 0.942 & 0.946 & 0.959 & $\pm 0.1 \%$ & $(-)$ \\
\hline $\bar{u}_{m} / \bar{u}_{\max }$ & 0.523 & 0.554 & 0.632 & 0.715 & 0.730 & $\pm 2.0 \%$ & $(-)$ \\
\hline$S=T_{p} / T_{s}$ & 2.34 & 1.31 & 0.78 & 0.52 & 0.50 & $\pm 2.0 \%$ & $(-)$ \\
\hline
\end{tabular}

Fig. 4.2: Distribution of dimensionless time-averaged velocity ${ }^{9} \bar{u} / \bar{u}_{m}(-)$, for manifold B using cylinder head

The dimensionless scavenging number $S$ is much smaller for manifold B compared to manifold A. This difference is due to the large pre-cat mixing chamber volume of manifold B, and due to the fact that manifold B features four runners compared to three for manifold $\mathrm{A}$, which implies a smaller pulsation period $T_{p}$ for an identical engine speed. 
Values of $S$ smaller than unity indicate that the pulsation period is smaller than the scavenging time scale. In this case, a substantial degree of interference between consecutive flow pulses can be expected, and thus a significant influence of engine speed on the flow distribution. This is confirmed by the data in Fig. 4.2, at least by the mean-to-maximum velocity ratio. The flow uniformity index appears rather insensitive to this difference, which makes it too optimistic, and thus less suitable as a uniformity measure.

Since the engine speed dependence of manifold B is more pronounced, a broader engine speed range is used than for manifold A. Several measurements have been repeated for flow rates higher and lower than $70 \mathrm{Nm}^{3} / \mathrm{h}$. The comparison with steady flow experiments is discussed in $\S 4.3$.

\subsubsection{Crank angle resolved}

Fig. 4.3, Fig. 4.4 and Fig. 4.5 show the crank angle resolved ${ }^{10}$ mean dimensionless velocity and flow uniformity index for all investigated geometries ( $70 \mathrm{Nm}^{3} / \mathrm{h}$, comparable engine speed). Indicated in grey is the dimensionless exhaust valve lift (-). For the rotating valve, this is the equivalent exhaust valve lift that results in the same cross-sectional area as the rotating valve opening.

\footnotetext{
${ }^{10}$ The reference position $\left(0^{\circ} \mathrm{ca}\right)$ is the maximum open position for runner 1
} 
(a)

manifold $\mathrm{A}$, rotating valve, dynamic $(1452 \mathrm{rpm})$ mean axial velocity $\mathrm{u}_{\mathrm{m}}(-)$

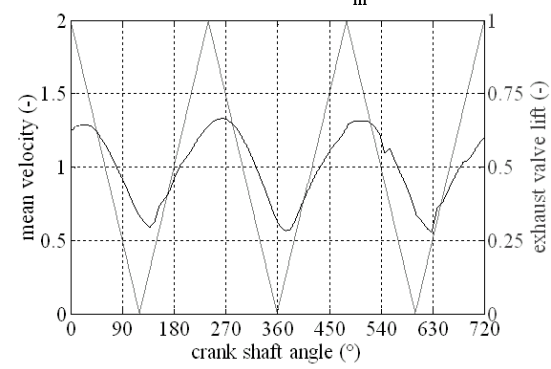

manifold $\mathrm{A}$, rotating valve, dynamic (1452 rpm) flow uniformity index (-)

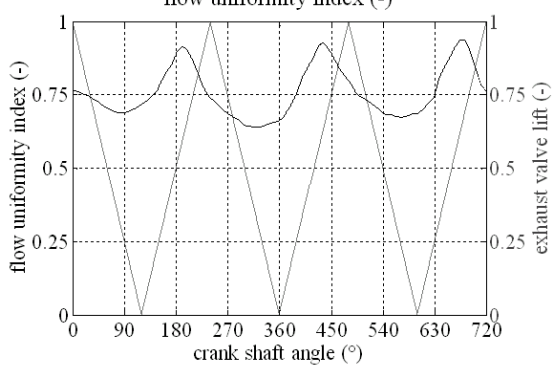

(b)

manifold $\mathrm{A}$, rotating valve, dynamic $(2132 \mathrm{rpm})$ mean axial velocity $\mathrm{u}_{\mathrm{m}}(-)$

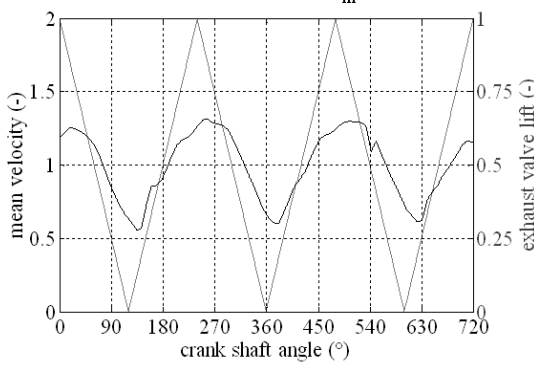

manifold A, rotating valve, dynamic (2132 rpm) flow uniformity index (-)

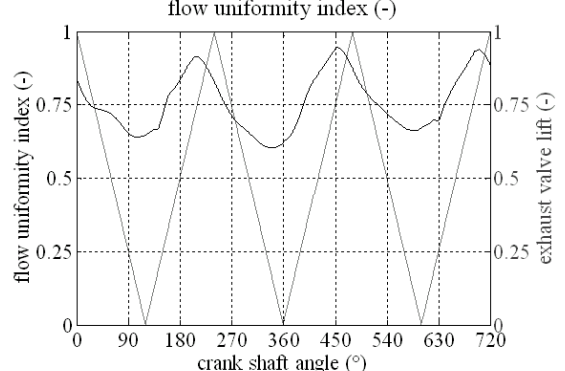

(c)

manifold A, rotating valve, dynamic (2822 1pm) mean axial velocity $\mathbf{u}_{\mathbf{m}}(-)$

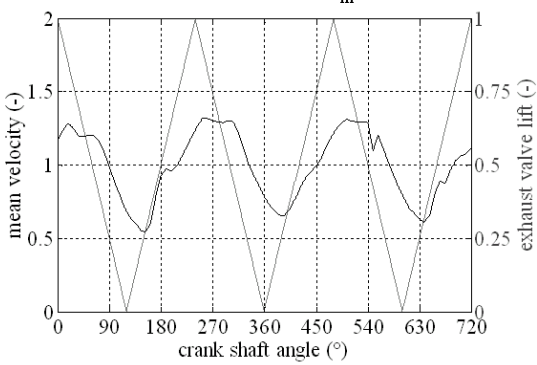

manifold $\mathrm{A}$, rotating valve, dynamic (2822 1pm) flow uniformity index (-)

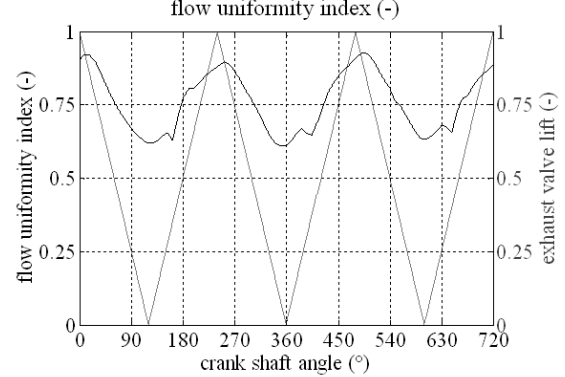

\begin{tabular}{cccccc}
\hline & $(\mathrm{a})$ & $(\mathrm{b})$ & $(\mathrm{c})$ & & \\
\hline$N$ & 1452 & 2132 & 2822 & $\pm 0.5 \%$ & $(\mathrm{rpm})$ \\
\hline $\bar{u}_{m}$ & 5.62 & 5.55 & 5.36 & $\pm 0.1 \%$ & $(\mathrm{~m} / \mathrm{s})$ \\
\hline$\gamma$ & 0.863 & 0.872 & 0.873 & $\pm 0.1 \%$ & $(-)$ \\
\hline
\end{tabular}

Fig. 4.3: Crank angle resolved dimensionless mean velocity $u_{m} / \bar{u}_{m}(-)$ (top) and flow uniformity index $\gamma(-)$ (bottom), for manifold A using rotating valve, at different engine speeds

(a)

manifold A, cylinder head, dynamic $(1327 \mathrm{rpm})$ mean axial velocity $\mathrm{u}_{\mathrm{m}}(-)$

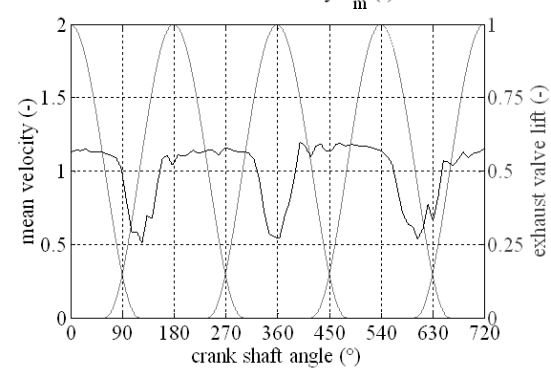

manifold A, cylinder head, dynamic (1327 rpm) flow uniformity index (-)

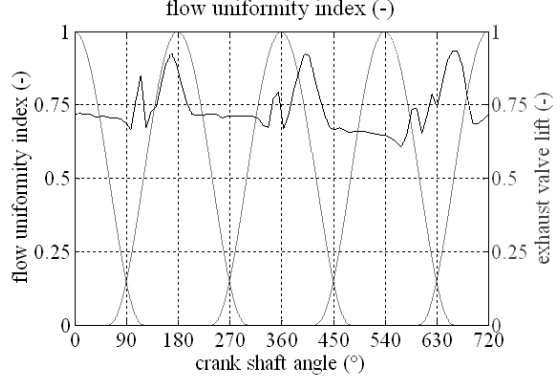

(b)

manifold A, cylinder head, dynamic (2001 rpm)

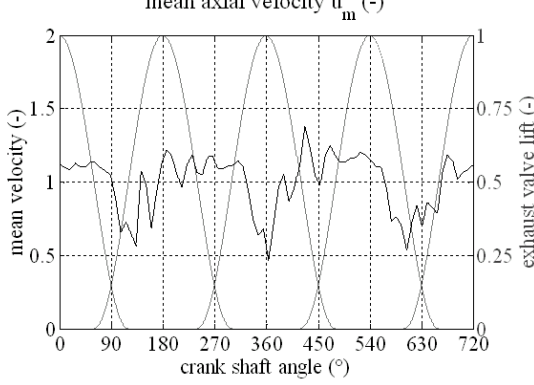

manifold A, cylinder head, dynamic (2001 rpm) flow uniformity index (-)

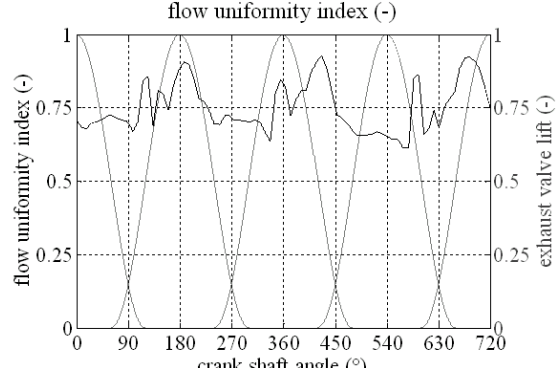

(c)

manifold A, cylinder head, dynamic $(2800 \mathrm{rpm})$

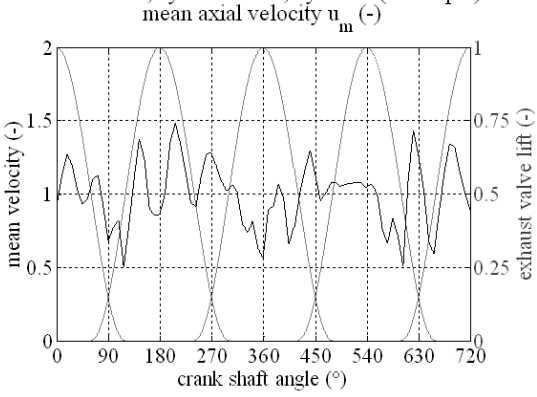

manifold A, cylinder head, dynamic (2800 rpm) flow uniformity index $(-)$

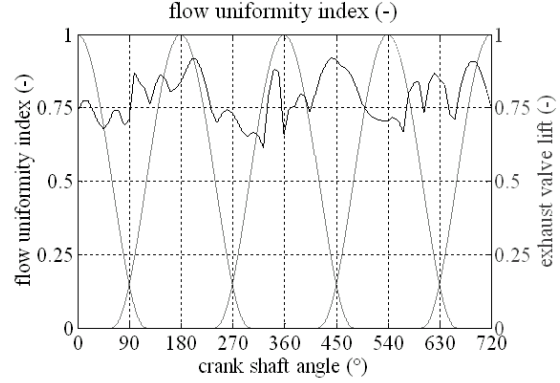

\begin{tabular}{cccccc}
\hline & (a) & (b) & (c) & & \\
\hline$N$ & 1327 & 2001 & 2800 & $\pm 0.5 \%$ & $(\mathrm{rpm})$ \\
\hline $\bar{u}_{m}$ & 5.52 & 5.77 & 5.54 & $\pm 0.1 \%$ & $(\mathrm{~m} / \mathrm{s})$ \\
\hline$\gamma$ & 0.860 & 0.867 & 0.895 & $\pm 0.1 \%$ & $(-)$ \\
\hline
\end{tabular}

Fig. 4.4: Crank angle resolved dimensionless mean velocity $u_{m} / \bar{u}_{m}(-)$ (top) and flow uniformity index $\gamma(-)$ (bottom), for manifold A using cylinder head, at different engine speeds 
(a)

manifold B, cylinder head, dynamic (1203 rpm) mean axial velocity $u_{m}(-)$

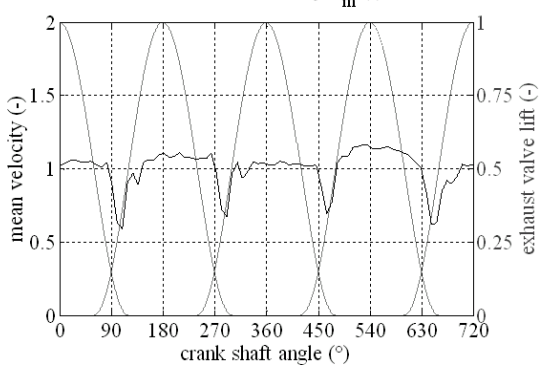

manifold B, cylinder head dynamic (1203 rpm)

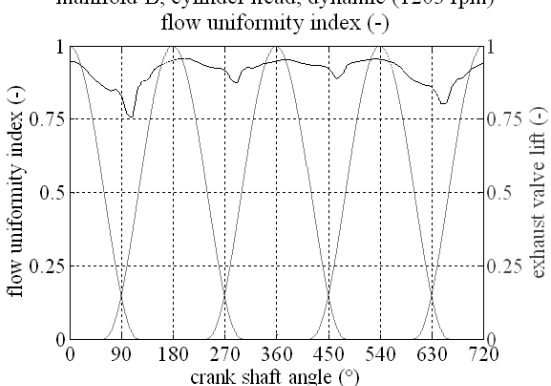

(b)

manifold B, cylinder head, dynamic (2002 1pm) mean axial velocity $u_{m}(-)$

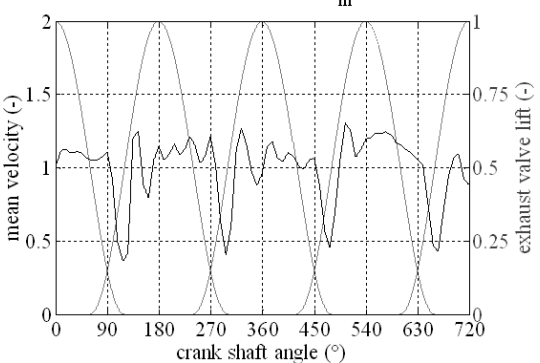

manifold B, cylinder head, dynamic (2002 rpm)

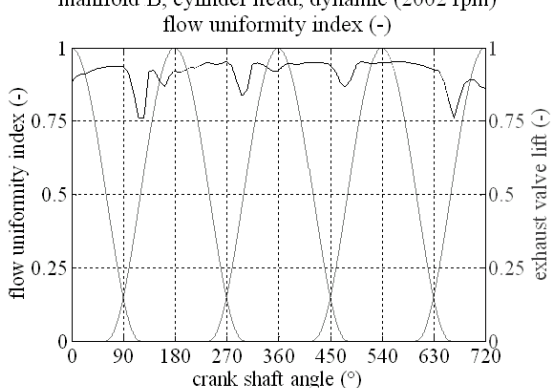

(c)

manifold B, cylinder head, dynamic (2803 rpm) mean axial velocity $u_{m}(-)$

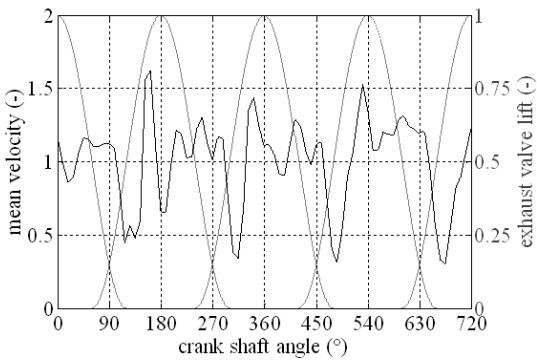

manifold B, cylinder head, dynamic (2803 rpm)

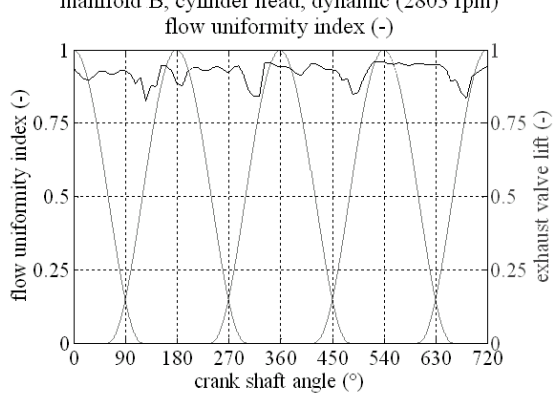

\begin{tabular}{cccccc}
\hline \multicolumn{1}{c}{$(\mathrm{a})$} & $(\mathrm{b})$ & $(\mathrm{c})$ & & \\
\hline$N$ & 1203 & 2002 & 2803 & $\pm 0.5 \%$ & $(\mathrm{rpm})$ \\
\hline $\bar{u}_{m}$ & 1.66 & 1.64 & 1.57 & $\pm 0.1 \%$ & $(\mathrm{~m} / \mathrm{s})$ \\
\hline$\gamma$ & 0.942 & 0.942 & 0.946 & $\pm 0.1 \%$ & $(-)$ \\
\hline
\end{tabular}

Fig. 4.5: Crank angle resolved dimensionless mean velocity $u_{m} / \bar{u}_{m}$ (-) (top) and flow uniformity index $\gamma(-)$ (bottom), for manifold B using cylinder head, at different engine speeds

A comparison of the crank angle resolved mean velocity for manifold A, using rotating valve (Fig. 4.3) and cylinder head (Fig. 4.4) shows that although the correlation coefficients in Table 4.1 indicate a high similarity on a time-averaged level, this is not the case when comparing the flow on the crank angle resolved level.

When displayed in chronological order, the crank angle resolved velocity distributions show the evolution of the flow inside the catalyst brick during a single engine cycle. Fig. 4.6 and Fig. 4.7 show a sequence ${ }^{11}$ of crank angle resolved velocity distributions during flow in runner 2, for manifold A using rotating valve and cylinder head. Close examination of these figures leads to the same conclusion as derived before based upon a comparison of mean velocities.

${ }^{11}$ Animations of unsteady velocity distributions can be consulted on the K.U.Leuven, dept. Mechanical Engineering website (http://www.mech.kuleuven.ac.be/tme/research/autoapps/). 


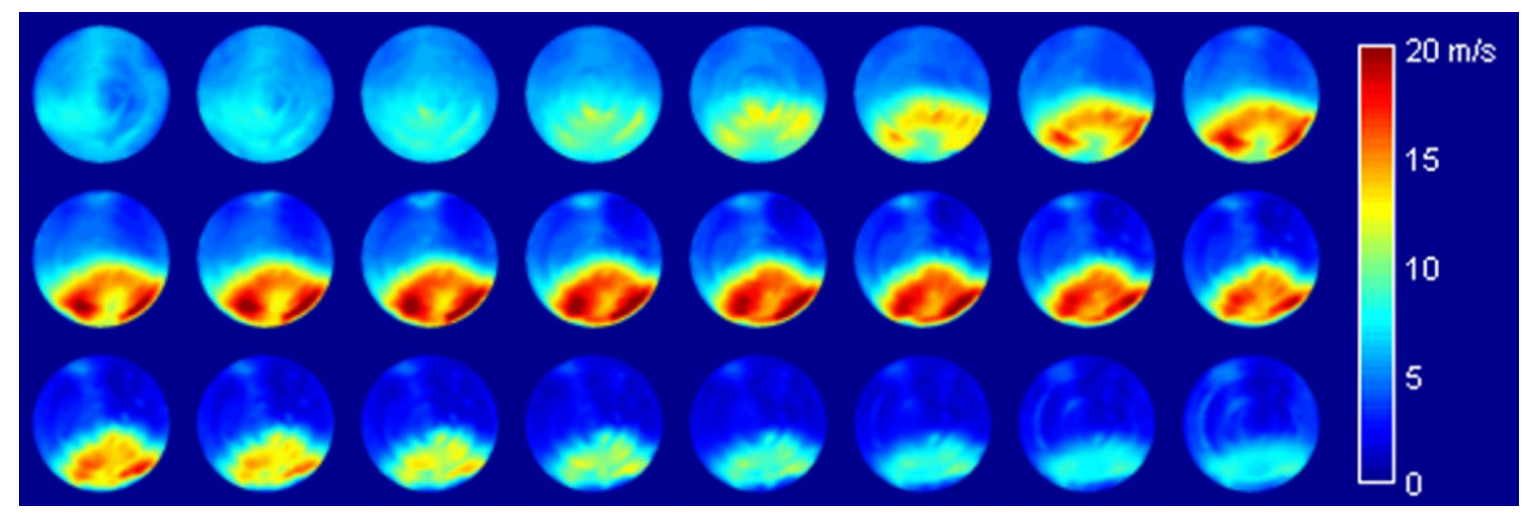

Fig. 4.6: Crank angle resolved velocity distributions $(0-20 \mathrm{~m} / \mathrm{s})$ for manifold A using rotating valve, during flow through runner 2 , in chronological order from left to right, top to bottom, from $405{ }^{\circ}$ ca to $612{ }^{\circ} \mathrm{ca}$, in steps of $9^{\circ} \mathrm{ca}\left(\right.$ at $1452 \mathrm{rpm}, 71.6 \mathrm{Nm}^{3} / \mathrm{h}$ )

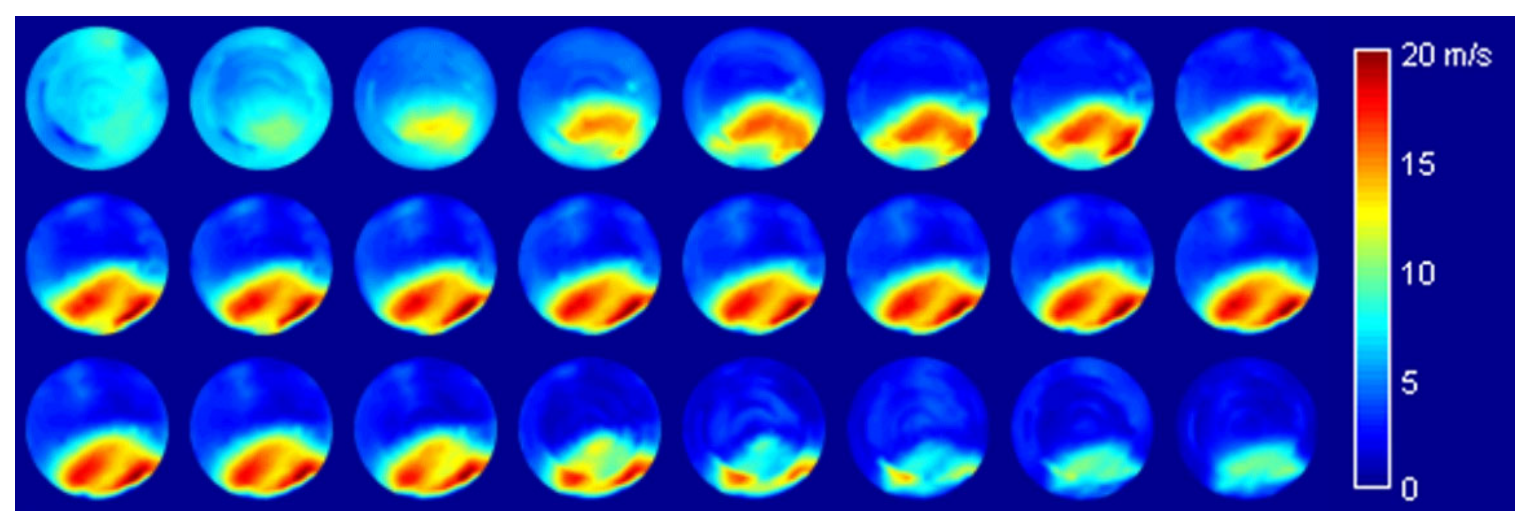

Fig. 4.7: Crank angle resolved velocity distributions (0 - $20 \mathrm{~m} / \mathrm{s})$ for manifold A using cylinder head, during flow through runner 2 , in chronological order from left to right, top to bottom, from $405^{\circ}$ ca to $612^{\circ} \mathrm{ca}$, in steps of $9^{\circ} \mathrm{ca}\left(\right.$ at $1327 \mathrm{rpm}, 68.2 \mathrm{Nm}^{3} / \mathrm{h}$ )

The origin of the unexpected mean velocity oscillation shown in Fig. $4.4 \mathrm{~b}, \mathrm{c}$ at higher engine speed is now further examined. Each value of mean velocity or flow uniformity index plotted in Fig. 4.3, Fig. 4.4 and Fig. 4.5 is calculated from a particular velocity distribution which in itself is the ensemble average of 25 velocity distributions. This results in a maximum estimated error of $1 \%$ on time-resolved mean velocity and flow uniformity index. Therefore, the mean velocity oscillations in Fig. 4.4b,c cannot be due to measurement errors.

The frequency of the oscillation in Fig. 4.4b,c ranges from 200 to $280 \mathrm{~Hz}$, independent of rotation speed or flow rate. Fig. 4.8 shows the catalyst mean velocity frequency spectrum of manifold A using rotating valve and cylinder head at $2800 \mathrm{rpm}$. 
(a)

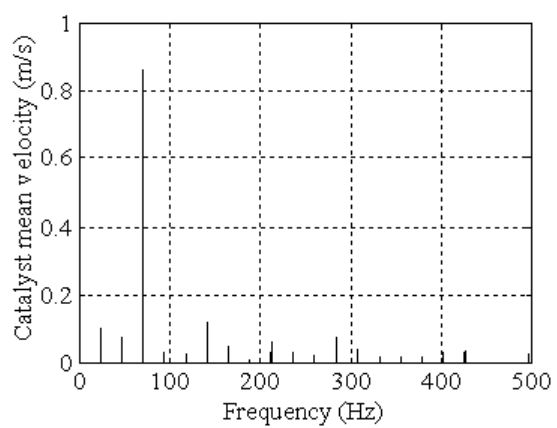

(b)

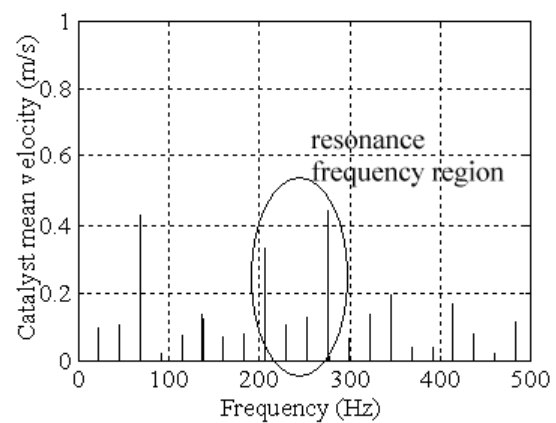

Fig. 4.8: Catalyst mean velocity frequency spectrum for manifold $A$ using (a) rotating valve and (b) cylinder head $\left(2800 \mathrm{rpm}, 70 \mathrm{Nm}^{3} / \mathrm{h}\right)$

It is assumed that the oscillations are caused by a Helmholtz resonance of manifold A. A Helmholtz resonator consists of a volume connected to a pipe, behaving as a spring-and-mass system with eigenfrequency

$$
f_{0}=\frac{1}{2 \pi} \frac{c}{L} \sqrt{\frac{A L}{V}}
$$

where $V=$ volume $\left(\mathrm{m}^{3}\right), L$ and $A=$ length (m) and cross-sectional area $\left(\mathrm{m}^{2}\right)$ of pipe and $c=$ speed of sound $(\mathrm{m} / \mathrm{s})$. The oscillation frequency from 200 to $280 \mathrm{~Hz}$ corresponds to the Helmholtz resonance frequency of the runner - pre-cat mixing chamber system, which ranges from 240 to $305 \mathrm{~Hz}$ according to Eq. 4.1, since the length of the different runners ranges from 90 to $150 \mathrm{~mm}$.

The rotating valve mean velocity evolution in Fig. $4.3 \mathrm{c}$ shows no oscillation comparable to the one in Fig. 4.4c. Fig. 4.8 confirms this. Furthermore, Benjamin et al. $(2001,2002)$ use a rotating disk as pulsating flow generator, which is somewhat similar to our rotating valve. Their results also show no mean velocity oscillation of the same magnitude as in Fig. 4.4b,c.

Two plausible causes are identified, explaining the different response of the cylinder head compared to the rotating valve: flow-induced excitation and mechanical excitation caused by the poppet valve motion. Concerning flowinduced excitation, the rotating valve on the one hand produces an essentially sinusoidal runner velocity, thus low amplitude harmonics in the resonance frequency range. On the other hand, the cylinder head's poppet valves produce an almost square wave runner velocity, with higher amplitude harmonics (Fig. 4.3 and Fig. 4.4 show the resulting catalyst brick mean velocity). In the case of the cylinder head, the amplitude of the runner velocity around $300 \mathrm{~Hz}$ is roughly 10 times higher than in the case of the rotating valve. A second plausible cause for 
the different response is the cylinder head's poppet valve excitation. The exhaust valves open for approximately $240{ }^{\circ} \mathrm{ca}$ (i.e. one third of the engine cycle) and are closed for the remaining two thirds of the engine cycle. Fig. 4.9 shows a frequency spectrum of the dynamic pressure excitation caused by the valve motion, assumed to be $p_{r e l}=-\operatorname{sign}\left(u_{v}\right)\left(C_{d} / 2\right)\left(\rho u_{v}^{2} / 2\right)$, with $C_{d}=\operatorname{drag}$ coefficient for circular plate, perpendicular to flow $(=1.11), u_{v}=$ valve velocity Fig. 4.9 shows that higher harmonic frequencies appear in the frequency spectrum due to the non-sinusoidal motion. When the engine speed increases above 2000 rpm, the band of the higher harmonics, indicated with ellipse in Fig. 4.9, shifts into the Helmholtz resonance frequency region from 240 to $305 \mathrm{~Hz}$. This explains the velocity oscillations when using the cylinder head as pulsating flow generator, while the rotating valve and rotating disk used by Benjamin et al. $(2001,2002)$ do not provide the same excitation magnitude.

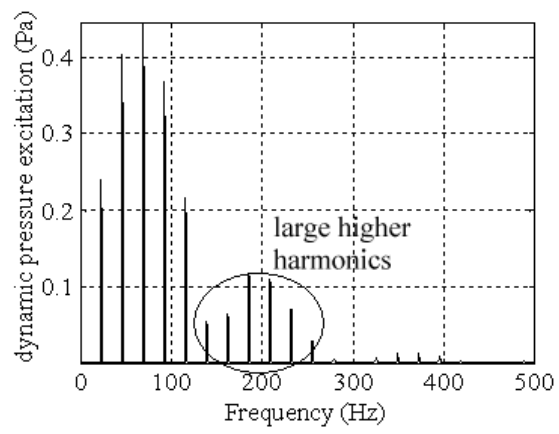

Fig. 4.9: Frequency spectrum of estimated relative pressure excitation caused by exhaust valve motion at $2800 \mathrm{rpm}$

A one-dimensional gas dynamic model of manifold A has been used to further verify the hypothesis of the origin of the mean velocity oscillation. The model uses a first order upwind differencing scheme to simulate compressible gas dynamics in the three runners. The scheme is a Simulink ${ }^{\mathrm{TM}}$ implementation of the upwind scheme introduced by Roe (1981), with 80 nodes in each runner. The precat mixing chamber is modelled as a zero-dimensional compressible volume, and the catalyst brick as a restriction with coefficients based on steady flow pressure drop experiments.

Fig. 4.10 shows results obtained with the one-dimensional gas dynamics model: the frequency response function of exhaust port pressure to catalyst velocity revealing the resonance frequencies. The Helmholtz resonance frequency 
ranges from 245 to $290 \mathrm{~Hz}$ since the runners have slightly different lengths. The first acoustic eigenfrequency appears at $1200 \mathrm{~Hz}$.

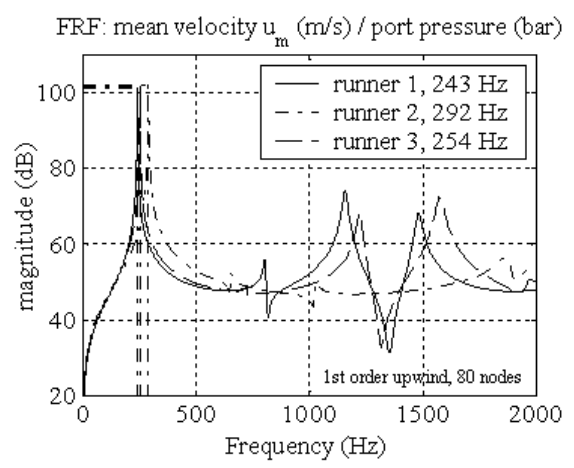

Fig. 4.10: One-dimensional gas dynamics model of manifold A: FRF of exhaust port pressure (bar) to catalyst mean velocity $u_{m}(\mathrm{~m} / \mathrm{s})$

Adam et al. (2002) use a gas exchange model with one-dimensional pipe flow to provide boundary conditions for three-dimensional CFD calculation of the transient flow field in a close-coupled catalyst manifold. Fig. 9 in their paper shows calculated velocity in each of the four runners, at $3000 \mathrm{rpm}$. The velocity after each blow-down oscillates at a certain frequency. One can distinguish the oscillation caused by the long runners ( 1 and 4) with a lower Helmholtz frequency (roughly $450 \mathrm{~Hz}$ ), and the short runners (2 and 3) with a higher Helmholtz frequency (roughly $580 \mathrm{~Hz}$ ).

All this considered, the mean velocity oscillations observed in our experiments should also appear in fired engine conditions. Although accurate time-resolved measurements on a fired engine are difficult to find, evidence for the existence of these Helmholtz oscillations is presented by Park et al. (1998): Fig. 5 in their paper presents results of their phase-locked LDA measurement in one runner of a CCC manifold in fired engine conditions, at $2000 \mathrm{rpm}$. Oscillations occur after the blow-down phase, which Park et al. assume to be caused by pressure waves. Roughly estimated from their figure, the frequency is around $300 \mathrm{~Hz}$, which is too low to be caused by pressure waves travelling back and forth. Most likely, their figure shows the same Helmholtz resonance as observed in our isothermal flow bench experiments.

The preceding argumentation demonstrates that the measured velocity oscillations are caused by a Helmholtz resonance that is typical for a manifold with close-coupled catalyst, mounted on a cylinder head. 


\subsection{Steady velocity measurements}

The steady velocity distributions are obtained by fixing the rotating valve or camshaft in a position corresponding to the maximum opening of each of the runners.

Fig. 4.11 shows the steady velocity distributions for manifold A obtained by fixing the rotating valve in each of the three maximum opening positions. Similar measurements were performed for the cylinder head and for manifold B.

(a)

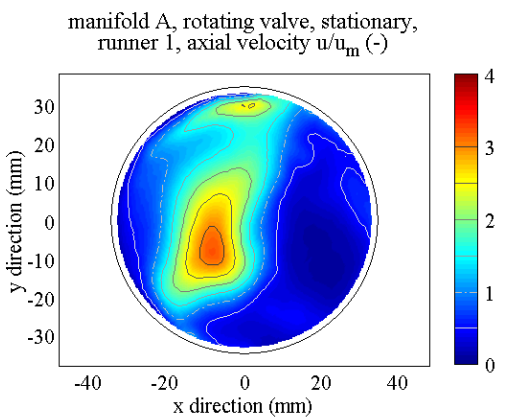

(b)

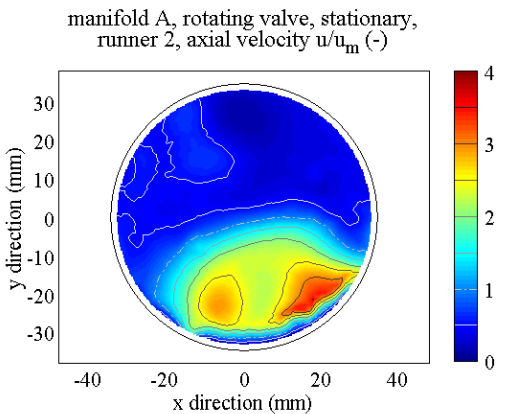

(c)

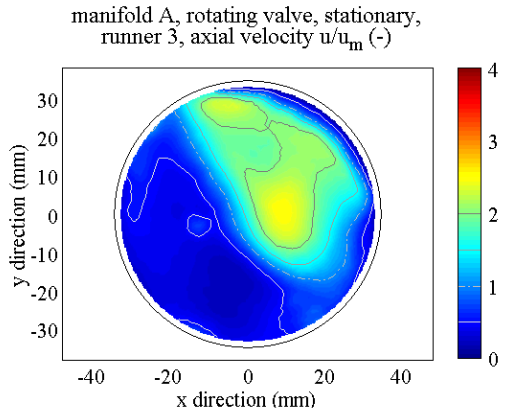

\begin{tabular}{cccccc}
\hline \multicolumn{7}{c}{ runner 1 } & runner 2 & runner 3 & & \\
\hline$u_{m}$ & $(\mathrm{a})$ & $(\mathrm{b})$ & (c) & & \\
\hline$R e$ & 6.23 & 5.94 & 6.11 & $\pm 0.3 \%$ & $(\mathrm{~m} / \mathrm{s})$ \\
\hline$Q$ & 58600 & 55900 & 57400 & $\pm 1.9 \%$ & $(-)$ \\
\hline$Q_{o}$ & 76.5 & 74.8 & 77.1 & $\pm 3.4 \%$ & $\left(\mathrm{Nm}^{3} / \mathrm{h}\right)$ \\
\hline$\gamma$ & 76.5 & 77.1 & 76.9 & $\pm 5.0 \%$ & $\left(\mathrm{Nm}^{3} / \mathrm{h}\right)$ \\
\hline$u_{m} / u_{\max }$ & 0.669 & 0.639 & 0.682 & $\pm 0.4 \%$ & $(-)$ \\
\hline
\end{tabular}

Fig. 4.11: Distribution of dimensionless velocity ${ }^{12} u / u_{m}(-)$, for manifold A using rotating valve, for steady flow through each of three runners

The objective of this research is to check the addition principle:

Does the time-averaged velocity distribution in pulsating flow correspond to a linear combination of velocity distributions, obtained for steady flow through each runner in maximum exhaust valve open position (with equal time-averaged flow rate in steady and pulsating flow)?

This linear combination is defined as the arithmetical average of the distributions of dimensionless velocity $\tilde{u}$, or symbolically:

$$
\tilde{u}_{\text {stat }}(x, y)=\frac{1}{n_{r}} \sum_{l=1}^{n_{r}} \tilde{u}_{\text {stat }, l}(x, y)
$$

\footnotetext{
12 Contour lines are 0.5 units apart, ranging from white to black, with a dashed contour at unity.
} 
where $\tilde{u}_{\text {stat }}$ is the averaged steady dimensionless velocity distribution and $\tilde{u}_{\text {stat }, l}$ are the $n_{r}$ individual steady dimensionless velocity distributions $\left(\tilde{u}=u / u_{m}\right)$ resulting from flow through runner $l$.

Fig. 4.12 shows the averaged steady dimensionless velocity distribution defined by Eq. 4.2 , at $70 \mathrm{Nm}^{3} / \mathrm{h}$, for each examined geometry: manifold A with (a) rotating valve and (b) cylinder head, (c) manifold B with cylinder head.

(a)

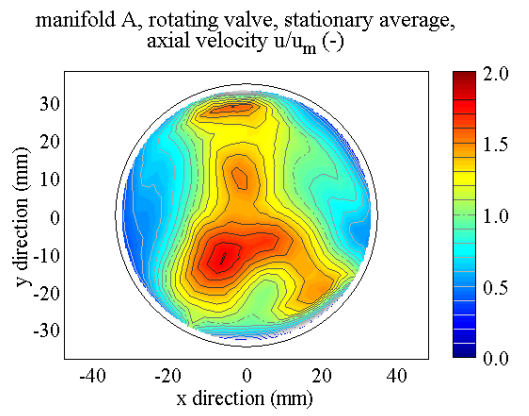

(b)

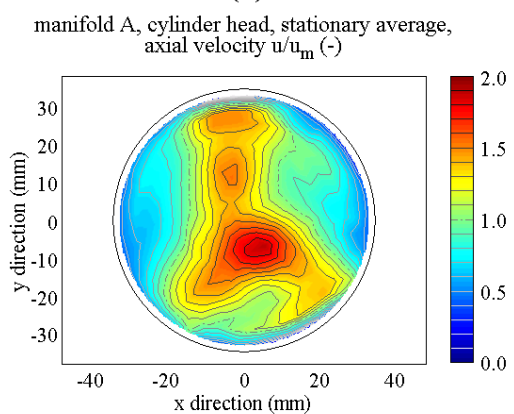

(c)

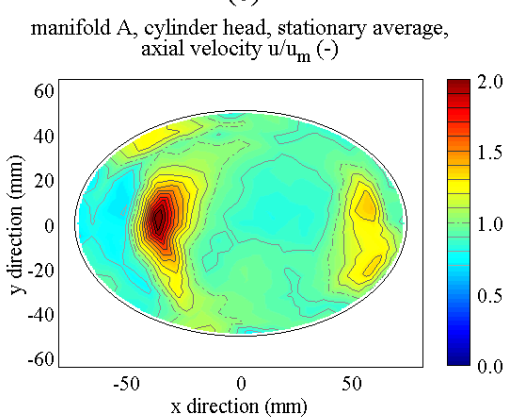

\begin{tabular}{|c|c|c|c|c|c|}
\hline & \multicolumn{2}{|c|}{ manifold A } & \multirow{2}{*}{$\begin{array}{c}\text { B } \\
\text { cylinder } \\
\text { head }\end{array}$} & & \\
\hline & $\begin{array}{l}\text { rotating } \\
\text { valve }\end{array}$ & $\begin{array}{c}\text { cylinder } \\
\text { head }\end{array}$ & & & \\
\hline & (a) & (b) & (c) & & \\
\hline$\gamma$ & 0.823 & 0.834 & 0.930 & $\pm 0.2 \%$ & $(-)$ \\
\hline$u_{m} / u_{\max }$ & 0.554 & 0.539 & 0.462 & $\pm 2.5 \%$ & $(-)$ \\
\hline
\end{tabular}

Fig. 4.12: Averaged steady distributions of dimensionless velocity ${ }^{9} u / u_{m}(-)\left(70 \mathrm{Nm}^{3} / \mathrm{h}\right)$, for each geometry

For the addition principle to be valid, this averaged steady dimensionless velocity distribution $\tilde{u}_{\text {stat }}$ should compare well with the distribution of timeaveraged dimensionless velocity measured at any given engine speed, with a timeaveraged flow rate of $70 \mathrm{Nm}^{3} / \mathrm{h}$. For manifold $\mathrm{B}$, flow rates higher and lower than $70 \mathrm{Nm}^{3} / \mathrm{h}$ have been tested as well. The results are discussed in $\S 4.3$.

\subsection{Comparison pulsating - steady flow}

Table 4.2 presents an overview of the comparison between each pulsating flow experiment and the corresponding averaged steady distribution, in terms of the shape similarity measure $r_{S}(-)$, the magnitude similarity measure $r_{M}(-)$, and the dimensionless scavenging number $S(-)$. 
Table 4.2: Similarity measures $r_{S}(-)$ and $r_{M}(-)$ for comparison of averaged steady velocity distributions with time-averaged unsteady velocity distributions

\begin{tabular}{cccccc}
\hline geometry & flow rate & $\mathbf{N}(\mathbf{r p m})$ & $\boldsymbol{S}(-)$ & $\boldsymbol{r}_{\boldsymbol{S}}(-)$ & $\boldsymbol{r}_{\boldsymbol{M}}(-)$ \\
\hline \multirow{2}{*}{$\begin{array}{c}\text { manifold A, } \\
\text { rotating valve }\end{array}$} & $70 \mathrm{Nm}^{3} / \mathrm{h}$ & 1452 & $4.37( \pm 2.2 \%)$ & $0.963( \pm 2.0 \%)$ & $1.125( \pm 15.9 \%)$ \\
\cline { 2 - 6 } & $70 \mathrm{Nm}^{3} / \mathrm{h}$ & 2132 & $2.91( \pm 2.1 \%)$ & $0.966( \pm 1.8 \%)$ & $1.165( \pm 15.8 \%)$ \\
\cline { 2 - 6 } & $70 \mathrm{Nm}^{3} / \mathrm{h}$ & 2822 & $2.13( \pm 2.1 \%)$ & $0.960( \pm 2.1 \%)$ & $1.148( \pm 15.7 \%)$ \\
\hline \multirow{3}{*}{$\begin{array}{c}\text { manifold A, } \\
\text { cylinder head }\end{array}$} & $70 \mathrm{Nm}^{3} / \mathrm{h}$ & 1327 & $4.56( \pm 2.2 \%)$ & $0.964( \pm 1.9 \%)$ & $1.162( \pm 18.1 \%)$ \\
\cline { 2 - 6 } & $70 \mathrm{Nm}^{3} / \mathrm{h}$ & 2001 & $3.19( \pm 2.2 \%)$ & $0.956( \pm 2.3 \%)$ & $1.224( \pm 17.0 \%)$ \\
\hline & $70 \mathrm{Nm}^{3} / \mathrm{h}$ & 2800 & $2.18( \pm 2.1 \%)$ & $0.941( \pm 3.1 \%)$ & $1.329( \pm 17.5 \%)$ \\
\hline & $45 \mathrm{Nm}^{3} / \mathrm{h}$ & 602 & $1.83( \pm 1.8 \%)$ & $0.815( \pm 9.4 \%)$ & $1.123( \pm 35.4 \%)$ \\
\cline { 2 - 6 } & $45 \mathrm{Nm}^{3} / \mathrm{h}$ & 1204 & $0.91( \pm 1.7 \%)$ & $0.638( \pm 17.4 \%)$ & $1.281( \pm 26.6 \%)$ \\
\cline { 2 - 6 } & $70 \mathrm{Nm}^{3} / \mathrm{h}$ & 608 & $2.35( \pm 1.8 \%)$ & $0.836( \pm 8.3 \%)$ & $1.155( \pm 48.1 \%)$ \\
\cline { 2 - 6 } manifold B, & $70 \mathrm{Nm}^{3} / \mathrm{h}$ & 1203 & $1.31( \pm 1.7 \%)$ & $0.704( \pm 14.5 \%)$ & $1.234( \pm 52.4 \%)$ \\
\cline { 2 - 6 } cylinder head & $70 \mathrm{Nm}^{3} / \mathrm{h}$ & 2002 & $0.78( \pm 1.7 \%)$ & $0.655( \pm 16.6 \%)$ & $1.445( \pm 41.5 \%)$ \\
\cline { 2 - 6 } & $70 \mathrm{Nm}^{3} / \mathrm{h}$ & 2803 & $0.52( \pm 1.6 \%)$ & $0.551( \pm 20.9 \%)$ & $1.600( \pm 34.3 \%)$ \\
\cline { 2 - 6 } & $70 \mathrm{Nm}^{3} / \mathrm{h}$ & 3595 & $0.50( \pm 1.6 \%)$ & $0.420( \pm 25.8 \%)$ & $1.613( \pm 38.6 \%)$ \\
\cline { 2 - 6 } & $70 \mathrm{Nm}^{3} / \mathrm{h}$ & 4402 & $0.41( \pm 1.6 \%)$ & $0.467( \pm 24.1 \%)$ & $1.622( \pm 42.0 \%)$ \\
\cline { 2 - 6 } & $100 \mathrm{Nm}^{3} / \mathrm{h}$ & 601 & $4.15( \pm 1.8 \%)$ & $0.939( \pm 3.2 \%)$ & $1.253( \pm 83.3 \%)$ \\
\hline & $100 \mathrm{Nm}^{3} / \mathrm{h}$ & 1204 & $2.16( \pm 1.7 \%)$ & $0.923( \pm 4.0 \%)$ & $1.295( \pm 82.7 \%)$ \\
\cline { 2 - 6 } & $115 \mathrm{Nm}^{3} / \mathrm{h}$ & 602 & $4.92( \pm 1.8 \%)$ & $0.940( \pm 3.1 \%)$ & $1.356( \pm 95.1 \%)$ \\
\hline $115 \mathrm{Nm}^{3} / \mathrm{h}$ & 1204 & $2.50( \pm 1.7 \%)$ & $0.931( \pm 3.6 \%)$ & $1.350( \pm 94.2 \%)$ \\
\hline
\end{tabular}

Concerning manifold A, close examination of Fig. 4.12a,b and Fig. 4.1a,b suggests that the distinction in the time-averaged velocity distribution shape between rotating valve (Fig. 4.1a) and cylinder head (Fig. 4.1b) is well preserved in the averaged steady velocity distribution (Fig. 4.12a,b). This is confirmed by the high correlation coefficients $r_{S}$ in Table 4.2.

In spite of the good correlation between the shapes of the velocity distributions, the averaged steady velocity distribution has a worse flow uniformity than the time-averaged velocity distribution in pulsating flow. Table 4.2 shows a relative difference of $12.5 \%$ to $32.9 \%$ between the mean-to-maximum velocity ratio in steady and pulsating conditions (remember the definition of $r_{M}$, see Eq. 3.7).

The comparison seems worse for manifold $\mathrm{B}$, as could be expected due to the exhaust valve overlap and the larger pre-cat mixing chamber volume, which results in smaller values of $S$, the dimensionless scavenging number.

The statistical significance of the correlation coefficient or shape similarity measure $r_{S}$ in Table 4.2 is determined using a statistical hypothesis test based on the Pearson correlation coefficient (see Hald (1952)). For these measurements ${ }^{13}$

\footnotetext{
13 This derivation is based on the largest possible subset of spatially independent measurement points. Spatial dependence is quantified using Moran's index, as defined in Cliff and Ord (1973). The different spatial dependence for the measurements on both manifolds accounts for the different limits.
} 
and based on a $95 \%$ confidence level, one can derive that two distributions are significantly correlated when:

$$
\begin{aligned}
& r_{S}>0.30, \text { for manifold A } \\
& r_{S}>0.25, \text { for manifold B }
\end{aligned}
$$

The statistical significance of the magnitude similarity measure $r_{M}$ in Table 4.2 is determined using Fieller's theorem (see Fieller (1940)), which defines a Student t-distributed test statistic for the ratio of two random variables with known distribution. The distribution of the mean-to-maximum velocity ratio is determined using Eq. 5.2.15 from Hald (1952). In the present case, two distributions with different magnitude $\left(r_{M}>1\right)$ still have a statistically similar magnitude when:

$$
\begin{aligned}
& r_{M}<1.26, \text { for manifold A } \\
& r_{M}<1.51, \text { for manifold B }
\end{aligned}
$$

These statistical significance limits for the similarity measures $r_{S}$ and $r_{M}$ constitute the boundaries for the addition principle's validity region.

It is interesting to plot the similarity measures $r_{S}$ and $r_{M}$ as a function of the dimensionless scavenging number $S$. $S$ combines engine speed, flow rate and manifold geometry in a single quantity with a clear physical interpretation (see §3.6). In Fig. 4.13b, the magnitude similarity measure $r_{M}$ is plotted versus $S$. Given the definition of $r_{M}$ (see Eq. 3.7), Fig. 4.13b shows the relative increase in flow uniformity for pulsating versus steady flow, as a function of $S$. The flow uniformity is always higher for pulsating flow than for the averaged steady distribution. This discrepancy between unsteady and steady flow uniformity increases as $S$ decreases (i.e. increasing engine speed, or decreasing flow rate per pre-cat chamber volume).

Fig. 4.13a presents the correlation coefficient $r_{S}$ of the averaged steady velocity distribution compared to the time-averaged velocity distribution in pulsating flow, as a function of $S$. Estimated error on $r_{S}$ ranges from $2 \%$ to $25 \%$, estimated error on $S$ is around $2 \%$. The following exponential curve fit is a good approximation of the empirical relationship between $r_{S}$ and $S$ :

$$
\hat{r}_{S}=1-0.801 \exp (-0.922 S)\left(\mathrm{R}^{2}=0.94\right)
$$

In addition, the empirical relationship between $r_{M}$ and $S$ can be fitted with an exponential curve, although the correspondence is worse than for $r_{S}$ :

$$
\hat{r}_{M}=1.220+1.326 \exp (-2.606 S)\left(\mathrm{R}^{2}=0.78\right)
$$


Based on the statistical significance limits for $r_{S}$ and $r_{M}$ (see Eqs. 4.3, 4.4), one can conclude that all data points in Fig. 4.13 represent a statistically significant similarity between the velocity distributions in steady and pulsating flow, except in the region of low dimensionless scavenging number $(S<0.5)$.

(a)

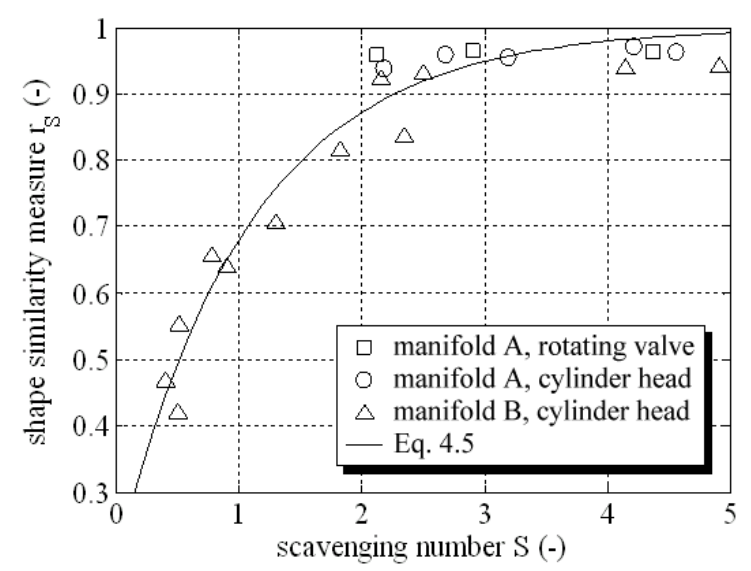

(b)

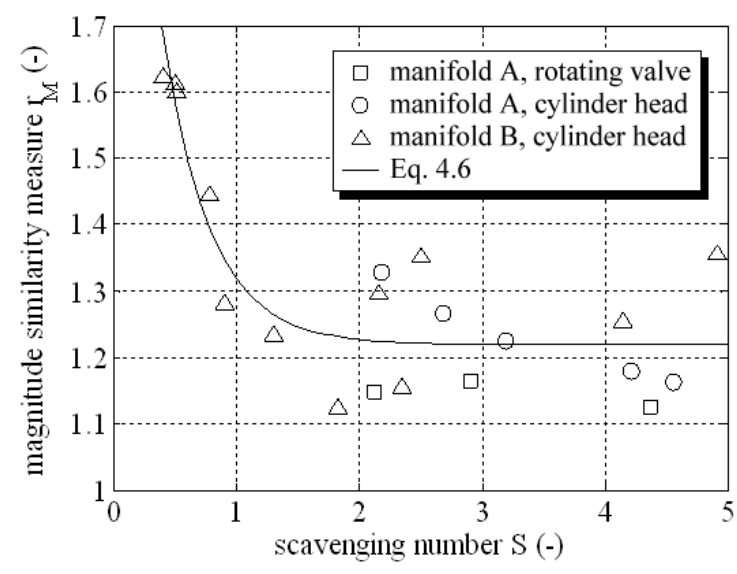

Fig. 4.13: Correlations as a function of dimensionless scavenging number $S$ (-) of (a) shape similarity measure $r_{S}(-)$ and (b) magnitude similarity measure $r_{M}(-)$

The combination of both similarity measures $r_{S}$ and $r_{M}$ quantifies the validity of the addition principle, based on the shape and magnitude similarity of the velocity distribution in steady and pulsating flow. Thus, not only does Fig. 4.13 represent proof of the validity of the addition principle, it also quantifies the dependence of the addition principle validity on the dimensionless scavenging number $S$.

In that sense, Fig. 4.13 and correlations 4.5, 4.6 can be used as a design tool, to decide whether or not the application of the addition principle (i.e. predicting time-averaged flow distribution in pulsating flow based only on the knowledge of steady velocity distributions) is justifiable, keeping in mind the statistical significance limits. The steady velocity distributions can be predicted either using steady CFD calculations, at least using a validated CFD code, or alternatively using a time-averaged velocity measurement technique in a steady flow rig. In any way, the steady flow distributions in combination with the addition principle yield a prediction of the flow uniformity in pulsating flow.

The present results are confirmed to some extent by findings from other researchers. Benjamin et al. (2002) define $J(-)$ as the ratio of pulsation period to diffuser residence time. $J$ is thus very similar to the dimensionless scavenging number $S$. Fig. 14a,b in their paper shows a correlation of non-uniformity index 
versus $J$. Upon converting the y-axis values from non-uniformity into uniformity indices, their figure compares qualitatively to Fig. 4.13b. Indeed, plotted in Fig. $4.13 \mathrm{~b}$ is $r_{M}$, which equals by definition (Eq. 3.7) a flow uniformity measure (based on the mean-to-maximum velocity ratio) in pulsating flow, relative to the corresponding uniformity measure in steady flow. Therefore, the increasing flow uniformity in pulsating flow for decreasing $S$ is confirmed by Fig. 14a,b in Benjamin et al. (2002).

Bressler et al. (1996) define GEN (-) as the ratio of exhausted gas volume per cylinder per cycle to the pre-cat mixing chamber volume. Upon multiplying numerator and denominator of this ratio by the engine speed $N$, it becomes clear that $G E N$ is proportional to $S$. Although no correlation is given by Bressler et al., their conclusions indicate that flow uniformity in pulsating flow is unaffected by engine speed when GEN remains constant. The flow uniformity in pulsating flow is always higher than for steady flow. Furthermore, the deviation between the flow uniformity in pulsating flow and steady flow is minimal for high $G E N$ and increases for decreasing GEN.

\section{Conclusions}

The addition principle states that the time-averaged velocity distribution in pulsating flow is proportional to a linear combination of velocity distributions, resulting from steady flow through each runner, as defined by Eq. 4.2.

The experimental results and subsequent data reductions have led to a statistically quantified proof of the validity of the addition principle for both a 3runner exhaust manifold (with non-overlapping exhaust valves) and a 4-runner manifold (with $60^{\circ}$ ca overlapping exhaust valves). Fig. 4.13 and correlations 4.5, 4.6 quantify this validity in terms of two dimensionless similarity measures $r_{S}$ and $r_{M}$ and the dimensionless scavenging number $S$, which incorporates engine speed, flow rate and geometry into a single parameter with a clear physical interpretation (see §3.6). Fig. 4.13 and correlations 4.5, 4.6 can be used to decide upon the applicability of the addition principle for a geometry, similar to our investigated geometries. The addition principle holds for $S>0.5$. This conclusion allows design engineers to predict the time-averaged catalyst velocity distribution in pulsating flow conditions from the knowledge of steady velocity distributions. The latter can be predicted either using steady CFD calculations, using a validated 
CFD code, or alternatively using a time-averaged velocity measurement technique in a steady flow rig.

Since the conclusions of this work pertain to a system without sonic blowdown, care should be taken in extrapolating the validity of the addition principle towards fired engine conditions. A new experimental set up is under construction, to investigate the effect of sonic blow-down on the present conclusions.

Although phase-locked hot-wire anemometry is not a new measurement technique, its application in full flow field studies of automotive exhaust systems has not been researched to the fullest extent. The measurement technique has provided detailed crank angle resolved information of the flow inside the exhaust manifold. This information is very useful for validating CFD predictions of pulsating flow. Ensemble averaging has reduced estimated experimental uncertainty on local velocity below $2.0 \%$ in pulsating flow conditions.

The phase-locked technique has revealed a strong Helmholtz resonance that would not have been observed using a time-averaged measurement technique. This resonance phenomenon is explained in detail using one-dimensional gas dynamic simulations, and has been observed in close-coupled catalyst manifolds by other researchers. The addition principle's validity was unaffected by this Helmholtz resonance.

\section{Acknowledgements}

The authors wish to thank L. Helsen for the assistance with the experiments and A. Michiels for the assistance in realizing the experimental set up. This work has been supported by IWT-Vlaanderen, under grant VLIET/970375/BOSAL.

\section{References}

1 Adam M; Heinrich M; Hopp M; Lang O (2002) Optimierung von Abgasanlagen mit analytischen Methoden. Motortechnische Zeitschrift (MTZ) 63 (2002) 10:838-846.

2 Arias-Garcia A; Benjamin S F; Zhao H; Farr S (2001) A comparison of steady, pulsating flow measurements and CFD simulations in close-coupled catalysts. SAE Paper 2001-01-3662.

3 Benjamin S F; Roberts C A; Wollin J (2001) A study of the effect of flow pulsations on the flow distribution within ceramic contoured catalyst substrates. SAE Paper 2001-01-1996.

4 Benjamin S F; Roberts C A; Wollin J (2002) A study of pulsating flow in automotive catalyst systems. Experiments in Fluids 33 (2002) 629-639.

5 Bressler H; Rammoser D; Neumaier H; Terres F (1996) Experimental and predictive investigation of a closecoupled catalyst converter with pulsating flow. SAE Paper 960564. 

flow uniformity. SAE Paper 2000-01-0865.

7 Bruun H H (1995) Hot-Wire Anemometry - Principles and Signal Analysis. Oxford University Press.

8 Clarkson R J (1995) A theoretical and experimental study of automotive catalytic converters. Ph.D. Thesis, Coventry University (UK).

9 Cliff A D; Ord J K (1973) Spatial autocorrelation. London: Pion.

10 Comfort E H (1974) Monolithic catalytic converter performance as a function of flow distribution. ASME Winter Annual Meeting, 74-WA/HT-30.

11 Fieller E C (1940) The biological standardization of insulin. J. Royal Stat. Soc. Suppl. 7: 1-64.

12 Hald A (1952) Statistical theory with engineering applications. New York: John Wiley \& Sons.

13 Hwang K; Lee K; Mueller J; Stuecken T; Schock H J; Lee J-C (1995) Dynamic flow study in a catalytic converter using laser doppler velocimetry and high speed flow visualisation. SAE Paper 950786.

14 Incropera F P; DeWitt D P (1996) Introduction to heat transfer. John Wiley \& Sons.

15 Kim H S; Min K; Myung C-L; Park S (2002) A combined experimental and computational approach to improve catalyst flow uniformity and light-off behaviour. Proc. IMechE, Part D - Journal of Automobile Engineering, 216:413-430.

16 Lemme C D; Givens W R (1974) Flow through catalytic converters - an analytical and experimental treatment. SAE Paper 740243.

17 Missy S; Thams J; Bollig M; Tatschl R; Wanker R; Bachler G; Ennemoser A; Grantner H (2002) Computergestutzte Optimierung des Agbasnachbehandlungs-systems fur den neuen 1,81-Valvetronic-Motor von BMW. Motortechnische Zeitschrift (MTZ) 63 (2002) 1:18-29.

18 Nagel T; Diringer J (2000) Minimum test requirements for high cell-density, ultra-thin wall catalyst supports, Part I. SAE Paper 2000-01-0495.

19 Park S-B; Kim H-S; Cho K-M; Kim W-T (1998) An experimental and computational study of flow characteristics in exhaust manifold and CCC (close-coupled catalyst). SAE Paper 980128.

20 Roe P L (1981) Approximate Riemann solvers, parameter vectors, and difference schemes. Journal of Computational Physics. 43:357-372.

21 Ubaldi M; Zunino P; Barigozzi G; Cattanei A (1996) An experimental investigation of Stator induced unsteadiness on centrifugal impeller outflow. Journal of Turbomachinery - Transactions of the ASME, 118:(1),41-51

22 Voeltz S; Kuphal A; Lieske S; Fritz A (1999) Der Abgaskrummer-Vorkatalysator fur die neuen 1.01- und 1.41-Motoren von Volkswagen. Motortechnische Zeitschrift (MTZ) 60 (1999) 7/8:462-468.

23 Weltens H; Bressler H; Terres F; Neumaier H; Rammoser D (1993) Optimisation of catalytic converter gas flow distribution by CFD predicition. SAE Paper 930780. 